\title{
DATOS PARA UNA TIPOLOGÍA DE LA PARONOMASIA
}

\author{
Mario Garcfa-Page Sánchez
}

UNED

1. Aunque no existe unanimidad absoluta entre las definiciones propuestas en los diferentes manuales de poética y retórica ${ }^{1}$ se entiende comúnmente por paronomasia ( $\pi \alpha \rho \circ v \mu \mu \sigma \alpha \alpha)$ el juego lingüístico que se construye al poner en relación dos o más palabras fónicamente semejantes.

1 Vid. entre otros, FonTANier, P. (1830), Les figures du discours, Paris, Flammarion, 1968, 348; LAzaro Carreter, F. (1953), Diccionario de términos filologicos, Madrid, Gredos, 1971 (3." ed. corregida); SHIPLEY, J.T. (1955), Dictionary of world literary terms, Londres, George Allen \& Unwin LTd, s.v. pun; LAUSBERG, H. (1960), Manual de retórica literaria, Madrid, Gredos, II (1984) 114-8; MORIER, H. (1961), Dictionaire de Poétique et de Rhétorique, Paris, PUF, 3.^ ed.; PrEMINGER, A. (1965), Princeton Encyclopeida of Poetry and Poetics, Macmillan Reference Books, 1986, s.v. pun; MARCHESE, A. (1978), Dizionario di retorica e di stilistica, Milán, Amoldo Mondadori Editore, ${ }^{3} 1981$; SPANG, K. (1979), Fundamentos de retórica, Pamplona, Universidad de Navarra, 1984, 156-7; Beristán, H. (1985), Diccionario de retórica y poérica, México, Ed. Porrúa, S.A.; MARChESE, A.-FoRRADELlAS, J. (1986), Diccionario de retórica, critica y terminología literaria, Barcelona, Ariel; MARCos, F. (1989), Diccionario práctico de recursos expresivos (figuras y tropos), Cáceres, Univ. de Extremadura, etc.

Aparte de los manuales de poética y retórica, son escasos los estudios sobre el fenómeno de la paronomasia. Puede verse el estudio monográfico hecho por P. Valesio desde la perspectiva de la Gramática Generativa: (1972), «Paronomasia and the articulation of phonological rules», Proceedings of the Eleventh International Congress of Linguists, 2, 1005-1015; asi como el de V. GRiGoRIEV: (1978), «L'attraction paronymique», en Grigoriev, V. (ed.) (1981), Linguistique et Poétique, Moscú, Progrés, 324-331. 
Esta caracterización, aunque válida en numerosas ocasiones, no es menos laxa ${ }^{2}$ que la que, con el término de annominatio, proponían los retóricos latinos para dar cuenta de la variación de sentido que puede provocar aun la más leve alteración formal de una palabra. Pueden aducirse ejemplos que presentan modificaciones diversas:

1) ¡Rimar, remar al mediodía!

\section{(R. Alberti)}

2) La que suavemente crea tu frente. La que seca tu rosiro, la que enjuga tu rastro de aquellas lágrimas.

(V. Aleixandre)

Nuestro estudio sigue la línea del trabajo de J.A. MARTínEZ (1976), «Repetición de sonidos y poesía», $A O, 26,77-102$. Vid. igualmente el cap. 1 («Expresividad del material fónico: la paronomasia») de mi tesis: (1988), La lengua poética de Gloria Fuertes, Universidad Complutense de Madrid. En el presente trabajo se siguen las observaciones y revisiones hechas ya en el citado capítulo con relación a un trabajo anterior: GARCíA-PAGE, M. (1986), «Un artificio fónico recurrente en la lengua poética de Gloria Fuertes: la paronomasia», Revista de Literatura , 48, 96, 407-431.

Pueden consultarse, además: Alonso, D. (1943), «Poesía árabigoandaluza y poesía gongorinax, en (1955), Estudios y ensayos gongorinos, Madrid, Gredos, ${ }^{3} 1982,31-65 ;$ MART(NEZ, J.A. (1975), Propiedades del lenguaje poético, Universidad de Oviedo, Archivum, 436-9; Coll y Vehf, J. $\left(\mathbf{1 8 8 5}^{3}\right.$ ), Diálogos literarios (Retórica y Poética), Barcelona, Libr. J. y A. Bastinos, Editores, 307-312; SANCHEZ, A. (1961), «Aspectos de lo cómico en la poesía de Góngora», RFE, 44: 1-2, 95 138 (esp. 107-110); LLANo, M.T. (1984), La obra de Quevedo. Algunos recursos humoristicos, Salamanca, Univ. de Salamanca, 121-5, etc.

Cabe recordar en este punto cómo R. JAKOBSON se sirve del fenómeno de la paronomasia ( $l$ like Ike) para justificar sus tesis sobre la llamada «función poética*: (1960), «Linguística y poética», en (1963), Ensayos de linguística general, Barcelona, Ariel, 1984, 347-395. Otro ejemplo de paronomasia es el que propone M. RIFFATERRE para demostrar su teoría sobre la producción del «textom: (1978), Sémiotique de la poésie, París, Seuil, 1983: Amore more ore re. Vid. igualmente sus trabajos (1977), «Semantic overdetermination in poetry», PTL, 2, 1-19 y (1979), La production du texte, París, Seuil.

Frente a los ejemplos que suelen aducirse en los estudios sobre la paronomasia -procedentes, en su mayoría, de autores del Siglo de Oro-, el corpus de ejemplos del presente trabajo ha sido extraído de la poesía que, salvo raras excepciones si acaso, podríamos llamar contemporánea. Por ello, puede presumirse que la paronomasia es un fenómeno continuo, presente en toda época literaria.

2 Hablamos de kvaguedad» en la definición porque no siempre permite delimitar adecuadamente la paronomasia con respecto a otros fenómenos más o menos afines: calambur, parequema, derivatio, parequesis, antanaclasis, homoioteleuton, rima, aliteración, anagrama, etc. Por limitaciones de espacio, y por no desviarnos del objeto principal de este estudio, no será abordado este tipo de cuestiones relativas a la diferenciación de los procedimientos lingüísticos citados. 
3) La lona en el mar riela, En la luna gime el viento

(V. Huidobro)

4) roca que posa, no barro que pasa

(M. de Unamuno)

5) ... el tenebroso

que tiene brasas en los dedos, dados

para jugar al rododendro...

(G. A. Carriedo)

6) Especial espacial.

(G. Fuertes)

7) como un paisaje de Van Gogh sigue siendo paisaje encerrado y enterrado en su marco

(L. Rosales)

8) por el que escribe ¡ay! y se pone peana

(J. A. Valente)

9) Te veía, sentía y te bebía

(B. de Otero)

10) ¡Oh Cuba! ¡Oh curva de suspiro y barro!

(García Lorca)

11) $Y$ en tu regazo tiernamente prietas, piedras desnudas, tû acaricias piedras

(Casanova de Ayala)

12) y otro labio sereno, abril, sonoro

(B. de Otero)

13) que, dóciles, vencidos, fueron Euria de feria seca fue un destrozo rudo

(F. Brines)

14) Vela y no vuela. Así la mariposa más grande...

(V. Aleixandre)

15) y saltan las altas llamas purísimas...

(Dámaso Alonso)

16) Bajas de un hilo de Helios con tu gimnasia Helena y pajariarca

(C.E. de Ory) 
17) ¿por qué verdes veredas?

(R. Molina)

18) lanza de los dolores, corola de la cólera

(P. Neruda)

19) El patriarcal poeta, casi busto, bulto escueto de hueso y pensamiento

(García Baena)

20) ¿Era hombre, era hembra; fue un momento?

(R. Alberti)

21) Estás casi cangúrido con tus sienes de pérvida y sueñas emparvade con trillos ya telúricos

(A. Crespo)

\section{CAUSAS}

Como se ha podido observar en los ejemplos anteriormente citados, el parentesco fónico se consigue de modos diversos. Una paronomasia puede construirse a partir de una operación de permutación, de conmutación o de adición o supresión de un sonido ${ }^{3}$.

\subsection{Por conmutación}

\subsubsection{Vocálica:}

Se sustituyen uno o varios fonemas vocálicos:

22) ylvieron, bEbieron, trabajaron.:.

$$
\text { (L. Cernuda) }
$$

23) Que fAcha de fEcha

$$
\text { (G. Fuertes) }
$$

${ }^{3}$ Discrepamos de la caracterización que propone K. SPANG en [1983], «Semilogía del juego de palabras», en GARRIDO, M.Á. (ed) (1984), Teoria semiótica. Lenguajes y textos hispánicos, Madrid, CSIC, 1, 295-303. Según el citado autor, la paronomasia vendría definida exclusivamente por una operación de sustitución. 
24) diestra en volar sin dormirte en el vuelo, en no pEsar al pIsar en la tierra

(R. Alberti)

25) ...SOria

se puso sEria. Baeza

(B. de Otero)

26) rosa y blanca, yElada con un velo.

VOlada para siempre de mi rosa

(B. de Otero)

27) casIda a una casAda

(G. Fuertes)

28) cercA del cerco

(G. Fuertes)

29) por aquella pEdrea los pAdrea

(G. Fuertes)

30) Llamo a tu lamA

(G. Fuertes)

31) Nunca vi clAro lo del clEro

(G. Fuertes)

32) IIAs de trEs vuelos, la perdiz a tierra

(C. Rodríguez)

33) Un trabajador librE del libro

(G. Fuertes)

34) vas cúpula, aunque es cópula infinita

(R. Alberti)

35) en la nada hay más algo que algA

(G. Fuertes)

36) Libros de misa. Tules. YelOs. VelAs.

(B. de Otero)

Cuando se produce la conmutación de los fonemas vocálicos y se preservan solo las consonantes en su propio orden consecutivo, estos constituyen un 
esquema fijo con presuntas casillas vacías, huecos fónicos que habrán de llenar aquellos ${ }^{4}, v \cdot g r .:$

37) Insomne AdÁn de polvo en un EdÊn de sombras

(P. García Baena)

38) la mosquita pIsa y pAsa

pEsa y pOsa por la casa

(Casanova de Ayala)

39) que puso encima de las crEstas crIstQs

(G. A. Carriedo)

40) su cuerpo de campana gAlopa y golpEa

(P. Neruda)

41) pero el entendimiento pArA en pErO...

(M. de Unamuno)

42) Vagué a menudo, atravesé en tu bUscA bOsquEs y praderías

(L. Panero)

43) sé que $\mathrm{sOmOs} \mathrm{la} \mathrm{sUmA}$ de instantes sucesivos

(J. Hierro)

\subsubsection{Consonántica:}

Se sustituyen una o varias consonantes:

44) horas

deDicadas

\section{a delicadas}

manipulaciones

(A. González)

45) ...élitros

de duros Grillos, Brillos o sonidos nocturnos

(V. Aleixandre)

4 Vid. a este respecto: Aconso, A. (1940), La poesia de Pablo Neruda, Buenos Aires, Ed. Sudamericana, ${ }^{7} 1977,112-4$. 
46) Oh espejo de España.

YeRmo

yelmo...

$$
\text { (B. de Otero) }
$$

47) De noche, amaDa, amaRRa tu corazón al mío

(P. Neruda)

48) Pero yo que he tocado una vez las aguDas aguJas del pino

(J. Hierro)

49) ...Pero yo me salGo, salTo libre fuera de mí, escapo

(E. Prados)

50) hombre de Mucha Lucha y Luego Euego

(C.E. de Ory)

51) ViCente era viDente

(G. Fuertes)

52) si de algo positivo es la cerTeza: cerVeza

(G. Fuertes)

53) donde lleGan sonidos que no lleVan significado

(R. de Garciasol)

54) sin ver el mar, oler las roSas roJas

(F. Brines)

\subsubsection{Vocálica + Consonántica:}

Se sustituyen, al menos, una vocal y una consonante a la vez:

55) Te aliviarán, mar sabio Que entre cURvas te cOMbas (?)

$$
\text { (J. Guillén) }
$$

56) que pueden pORtar almas que pueden pAStar flores
(G. Fuertes)

57) tiburones de esCAma y esPUma

(P. Neruda) 
58) resbalando en las negras cOCinas y cABinas

(P. Neruda)

59) liVIdeces y PAlideces

(M. Machado)

60) iflrmes!

ifOrmeN fila!

(Gloria Fuertes)

61) los bEndiTos labradores, los bAndiDos caballeros
(A. Machado)

62) El arquERo arcAlCo

Bajo la arcADA eterna del arquERO arcANO

(V. Huidobro)

63) Tú brAMando, brEGando toro de hombria

(R. Albrit)

64) ... como cuerdas con tendoNEs y músculos tenDidos

(M. de Unamuno)

65) Anidando maNOjos de magnolias mojaDAs

(P. Neruda)

66) y también de violetas cortADas y cortiNas

$$
\text { (P. Neruda) }
$$

67) para una iNfAnta DifUnta

(G. Fuertes)

68) ... y extraJO extrañA sombra, y la prendio

(V. Aleixandre)

69) rodeado de poderes que cruZAn y cruJEn

(P. Neruda)

70) Su Pompa RompE la cárcel precisa, y la pulpa ardiente 


\subsection{Por Inversión}

Otro de los procedimientos de consecución de la paronomasia consiste en la permutación de sus elementos fónicos repetidos. Generalmente, la permutación va acompañada de cualesquiera otras operaciones de producción: conmutación y adición (o supresión).

Se hablará de paronomasia quiásmica ${ }^{5}$ cuando los parónimos presentan el mismo grupo de sonidos iterados en distinto orden distribucional. La inverisón puede ser sólo de vocales, sólo de consonantes, o de vocales y consonantes al mismo tiempo.

\subsubsection{Vocálica:}

71) ... ¿En la marina panza del globo hace nuEvA nAvE su estela diamantina?

(A. Machado)

72) como Glauco, el dios mArIno mIrA, turbia la pulila de llanto, el mar,...
(A. Machado)

73) en el empEIne del pIE

$$
\text { (R. Alberti) }
$$

74) AdQrnada de OdA

$$
\text { (G. Fuertes) }
$$

75) Esos nervios eléctricos del más Alto voltAje (G. Fuertes)

76) poco a poco se habia $\mathrm{hEchO}$ de $\mathrm{nQchE}$

(M. de Unamuno)

5 MARTINEZ, J.A. (1976), 78-9. No obstante, cabe distinguir entre paronomasia «quiásmica» de inclusión o de intersección y paronomasia «quiásmica» de exclusión. En el primer caso, la permutación va añadida a una operación de adición o sustitución; en el segundo caso, se efectúa sólo una inversión de los elementos fónicos constitutivos (véase, más adelante, epígrafe 4.3.).

Para el concepto de quiasmo, vid. LAzaro Carreter, F. (1953), s.v.; cfr. Nordahl, H. (1971), «Variants chiasmiques. Essai de description formellew, Revue Romane, 6, 2, 219-232. 
77) En tu vientre, cual bloca de un escudo de tu blanco en la diana está la sombra

(M. de Unamuno)

78) Medio lado del mundo ErA de ArEna

(F. García Lorca)

79) 一 -siEmbra sin lluvia, recoge hAmbrE

(G. Fuertes)

80) No digas a un pOEtA pEAtÓn y extranjero

(R. Alberti)

81) —alejado sueño fijo de fantásticos acUAtios-: arAUcaias, magnolieros

(J.R. Jiménez)

\subsubsection{Consonántica:}

82) Crisolad oro en copela, y buRiLad LiRa y arco

\section{(A.Machado)}

83) y hace fulgir el cuerpo como una Luz aZul si la noche es de plomo

(V. Aleixandre)

84) Intervenid en el conflicto de puNtas que se diSputaN en lo más torionda de las justas

(C. Vallejo)

85) sólo si aCaSo de SaCo una cortina

(G. Fuertes)

86) ... Duró la vida en las ceNaS beSáNdote

(V. Aleixandre)

87) A que corazón irás, a derrumbarTe, qué Tumba pudrirá tus pobres huesos

(J. Hierro) 
88) a envejeCeR

como el ieReZ

(G. Fuertes)

\subsubsection{Vocálica + Consonántica:}

89) y todo tú, vibrante toro, suenas desde tu honda CARNE ENCARcelado

(R. Morales)

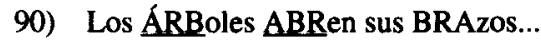

(G. Fuertes)

91) ...Entonces, DIME el reMEDIo, amigo

(L. Cernuda)

92) y no habrá una sola fuente que CORRA por su baRRAnCO

(F. Brines)

93) dura lo que el $\mathrm{ARCO}$ iris deCORAtivo y altamente peligroso

(G. Fuertes)

94) las flores aZULES huelen a imposible, entre dULCES LUCES

(J. R. Jiménez)

95) razones para olVIdar ollVares...

(B. de Otero)

96) y el cósmico siLEnClo de este CIELo

(R. Morales)

97) Medio monte de MinERVAs

ABRE sus BRAzos

(F. García Lorca)

98) que nuTRE nuEsTRA ARTEria

(G. Fuertes) 
La paronomasia quiásmica puede llegar a traspasar los límites de otro fenómeno linguístico, el anagrama ${ }^{6}$. La forma de escritura anagramática más representativa se consigue mediante la distribución de todos o casi todos los constituyentes fónicos en el mismo orden consecutivo pero en sentido inverso; v.gr.:

99) y en la noche redonda, CAUDALOSA, ASOLADA grita un hondo silencio la sombra en los jardines

(R. Morales)

100) la fresca aZUL LUZ de la mar

$$
\text { (F. Brines) }
$$

101) Donde unida está ya con la muerte la VIDA Y ADIVinas los cuerpos iguales a simiente

(L. Cernuda)

102) nORMA de AMOR de ti, hombre de Apolo (F. García Lorca)

${ }^{6}$ Como ocurre con la paronomasia, tampoco existe pleno acuerdo entre las definiciones que se proponen para el término de anagrama. Vid., p. c., LAZARO CARRETER, F. (1953), s.v. anagrama, Mounin, G. (1974), «Los anagramas de Saussure», en (1978), La literatura y sus tecnocracias, México, FCE, 1984, 100-8; JoHNSON, A.L. (1977), «Anagrammatism in poetry: theoretical preliminaires», PTL, 2, 89-118; RONAT, M. (1970), «Vers une lecture des anagrammes por la thérie saussierene», Change, 6, 119-126; Ivanov, V. (1974), «Growth of the theoretical framework of modern poetics», Current Trends in Linguistics, 2:2, 835-861 (esp. 835-841); TODOROV, T. (1978), «Les jeux de mots», en Les genres du discours, París, Seuil, 294-310 (esp. 307); GoYET, F. (1981), «La prueve par l'anagramme», Poetique, 46, 229-246.Vid. otros ejemplos en R. VILCHES (1955), Curiosidades literarias y malabarismos de la Lengua, Santiago de Chile, Nascimento, 41-48.

Para un mejor conocimiento sobre la teoría de F. DE SAUSSURE acerca del anagrama, pueden consultarse: Benveniste, E. (1964), «Lettres de Ferdinand de Sauusure à Antoine Meillet», CFS, 21, 89-130; JAKOBSON, R. (1971), «Le première lettre de Ferdinand de Saussure a Antoine Meillet sur Jes anagrammes», en (1973), Questions de poétique, París, Seuil, 190-201; y, especialmente, StARobinski, J. (1967), kLes mots sous les mots: textes inédits des cahiers d'anagrammes de Ferdinand de Saussure», To Honor Roman Jakobson. Essays on the occasion of his Seventieth Birthday, 1906-1917; trabajo ampliamente desarrollado en (1971), Les mots sous les mots. Les anagrammes de Ferdinand de Sasuure, París, Gallimard. Cf. Kristeva, J. (1966), «Para una semilogía de los paragramas», Semiótica (I), Madrid, Espiral/Ensayo, 1978, 227-69. 


\subsection{Por adición o sustracción}

De acuerdo con estas operaciones, uno de los parónimos presenta al menos un componente fónico más que el otro; es decir, un parónimo es fónicamente más extenso que el otro. La adición (o sustracción) puede ser de una vocal, de una consonante, o de ambas a la vez.

\subsubsection{Vocálica:}

103) Mas tu mano es garra. Agarra, toma color...

$$
\text { (C. Bousono) }
$$

104) ¿Acaso os Asombra mi sombra embozada(?)

$$
\text { (A. Machado) }
$$

105) Siempre tu pie de liEbre libre y loca

$$
\text { (C. E. de Ory) }
$$

106) Otros días vendrán, será entendido el silencio de plantas y planEtas

$$
\text { (P. Neruda) }
$$

107) ¡Que solO el sol, qué solo!

$$
\text { (J. R. Jiménez) }
$$

108) Belleza triste arcángel que con una pereza vespertina suAve sube

$$
\text { (C. E. de Ory) }
$$

109) vUela, que por ti yela. madre junto a su sueño, tu compalera

(R. de Garciasol)

110) No le deja en la mano el arOma del arma

(J. Hierro)

111) llanto con caUsa casa sin dintel del pobre

(B. de Otero) 


\subsubsection{Consonántica:}

112) Mujer casada.

casCada

(G. Fuertes)

113) voz en silencio, alma, en Calma

(R. Molina)

114) algo cegata la del alba Malva

(C. Rodríguez)

115) ...Desplegaron

sus Colores, olores y sonidos

(J. Hierro)

(116) Sin dejar ties'To tieso ni figurita en pie

(G. Fuertes)

117) ... el pedantículo que esculpe o escupe concienzudamente todos sus sinsabores

(V. Aleixandre)

118) Mi corazón también cantara el alme Salme de abril bajo la luna clara

(A. Machado)

119) Aunque tu amor no te dé Cama: ama

(G. Fuertes)

\subsubsection{Vocálica + Consonántica:}

120) La presencia de Dios en nuestras citas colgamos de las cítARas del río

(L. Panero)

121) para percibir de pronto el espectáculo, el circo, el cfrcULo, la arena

(J. A. Valente)

122) Ahora es la bOTella más bella que una flor

(J. Hierro) 
123) pero vino un vildano

(G. Fuertes)

124) Tanta pata y ningún brazo iqué broMazo;

(G. Fuertes)

125) ... No salTa

como sal en la lumbre...

(C. Rodríguez)

126) $Y$ la magia tiene ciencia

-yo PAciencia

(G. Fuertes)

127) atónito, adorándote, riendo, reNEgando, regando los rincones

(R. Alberti)

128) y su vaga baRRIga en donde duermen cadáveres con trigo

(P. Neruda)

129) Que EScojo mi corazón que ha sido cojo

(G. Fuertes)

130) De aquella tierra donde el sol MAdura lo que no dura
(C. Rodríguez)

131) Tras de tanto camino es la primera vez que viro brotar la primAVera

(A. Machado)

Tal es el emparentamiento fónico que contraen los segmentos paromásicos ${ }^{7}$ que lo que parece que se produce es la repetición de una misma palabra. Esta aparente reiteración léxica ${ }^{8}$ se consigue por medio de un falso fenómeno de:

7 Se entiende por «segmento paronomásico» el grupo de sonidos comunes (recurrentes) a dos palabras que establecen entre sí una relación de paronomasia.

${ }^{8}$ En este sentido, H. LAUSBERg (op. cit.) considera la paronomasia como una forma de «repetición relajada de una palabran. Cf. con el concepto de metaplasmo. Vid., p. e., Grupo $\mu$ (1970), Retórica general, Barcelona, Paidós, 1987, cap. 2. 
a) Aféresis (o prótesis):

132) Tres años: $y$ cien Caños de sangre abel sin nombre (B. de Otero)

133) LLamarle fue amarle

(G. Fuertes)

134) Toda la mar como una ola Sola se levanta...

(M. de Unamuno)

135) Vive en nosotros. Quiere herimos. Entro Dentro de ti. Aúlla, ruge, brama.

(J. Hierro)

136) cielo del alba primordial, divine Adivino en tus ojos

(M. de Unamuno)

137) Despacio espacio

(G. Fuertes)

138) Lola era una ola

(R. Alberti)

139) que en el suelo se ajan,

Bajan floridos

(M. de Unamuno)

140) evitar Levitar

(G. Fuertes)

141) Color: olor: mis venas saben a ti: allí te abres

(V. Aleixandre)

b) Síncopa (o epéntesis):

142) en un bosque de palmas, de palOmas dobladas (V. Aleixandre)

143) liEbre libre

(G. Fuertes) 
144) Se asomó al borde mudo de aquel muNdo de piedra

(J. Hierro)

145) dobladas como ramas bajo el peso de la belleza cálida caída

(A. González)

146) a iguales, $y$ escribir mientras bebe tu bReve orina ávidamente, pajjaro

$$
\text { (L. M. Panero) }
$$

147) un páliDo palio llevo, un cortejo evidente (P. Neruda)

148) ... de la ceremonia $y$ del rito, en el ritMo que nos congrega...

(Á. González)

149) Mujer casada, caNsada

(G. Fuertes)

150) porque $\mathfrak{s}$, porque es sino y siGno y simulacro

(C. Bousoño)

c) Apócope (o paragoge):

151) amasando su sinQ, sin historia

(R. de Garciasol)

152) Que por desierto al sol he caminado solO

(L. Cernuda)

153) mi amoR y mi amo

(G. Fuertes)

154) AsiR asi el paisaje precario de tu cuerpo

(V. Aleixandre) 
La paronomasia puede haberse construido por medio de la combinación de dos modos de consecución diferentes; por ejemplo:

a) inversión + conmutación:

155) ... no fue una aureola sino sólo el único senTaDO senSaTo

(C. E. de Ory)

156) trasegadas mulEtAs, mulAlOs agua y fuego

(S. Sernesi)

157) Eñe de cAf̃O de fuente, eñe de çŨ̃ que injerta

(G. Fuertes)

158) rezaban para que no sONARa la sIRENa

(G. Fuertes)

159) Lengua de mar que subes por el vAllE a la yIllA los pies hasta lamerla

(M. de Unamuno)

160) La maÑaNa, se pierde en la maRaÑa

(G. Fuertes)

161) No es que el dolor te $\mathrm{CApE}$, es que te $\mathrm{COpA}$, te CAPicúa

(G. Fuertes)

b) inversión + adicion:

162) ¿Qué vieja y sabia historia cuEntA a cuAntOS quieren escucharla

(J. Hierro)

163) Y tu QSCura locura en mi clara CQRDura

(G. Fuertes)

164) para que el $\ A s O$ REbosE hay que llenarlo primero

(A. Machado) 
165) y descanso a los ojos, hoy hErIda

OtEAda de sueño y lejanía

(R. de Garciasol)

166) Escúchame, Soy la AvisPA IMPREvisTa

(v. Aleixandre)

167) Hombres tristes retornan junto al mUno mOrADO

(J. R. Jiménez)

168) canto y se ENcAja mi quEja

(G. Fuertes)

3. La paronomasia es un fenómeno lingüístico de naturaleza fónica y no gráfica, como se pone de manifiesto a través de esta serie de ejemplos:

169) ¡BeBo, del sueño que YiY̌o!

(C. Rodríguez)

170) Te he Vencido

y no me ceBo

(G. Fuertes)

171) ... sin un Yaso

de Beso candente

(G. Fuertes)

172) ¿Reina de la jardineŔa!

(R. Alberti)

173) ¿Voy al destieRRo del desieRto oscuro (!)

(M. de Unamuno)

174) ... sólo consistieRa

en tieRRa, en agua...

(B. de Otero)

175) Oigo pueblos de aYes y vaLLes de lamentos

(M. Hernández)

176) Estamos muy orgullosos con nuestro orgulLo, pero si yo arguYQ con el sufrimiento...

(B. de Otero)

177) Aún sigo echándome la ternura al Hombro por su vuelvo a encontrar Hombre o Hembra

(G. Fuertes) 
178) Creemos los nombres.

Derivarán los Hombres

(J. R. Jiménez)

179) No es la sola Hora la aurora

(C. Rodriguez)

180) Y en la ciudad - no en el Hampa y en la Pampa

hizo su propia conquista

(A. Machado)

181) ElaCos o FláCidos, sin cabellos, con lentes

(L. Cernuda)

182) Y había anchas aceras por aQUella Calle...

(V. Aleixandre)

183) Me pesa de lo que hice; en la estaCada se QUeda del pasado...

(M. de Unamuno)

Por la distinción fonológica vibrante simple $/ r /$-vibrante múltiple $/ \mathbf{T} /$, la relación paronomásica existente entre reina y jardineria, o entre destierro y desierto, no puede considerarse, respectivamente, de inclusión o de exclusión, sino de intersección ${ }^{9}$, rEINA $\cap$ (jardi) NEŕf es una falsa inclusión lo que se produce en 174): *consistTIERA $\supset$ TIERRA.

En virtud de la distinción fonológica entre el sonido velar oclusivo sordo $\mathrm{k} /$ y el sonido interdental fricativo sordo $/ \theta /$, correspondientes a lo segmentos gráficos $c+o$ y $c+i$ respectivamente, la relación entre flacos y flácidos no puede describirse como paronomasia de inclusión, sino de intersección: FLAcOS $\cap$ FLAçidOS.

Para los hablantes yeístas, existiría una paronomasia de inclusión en 175): AYES $\supset$ cALLES. En los casos en que se establece distinción fonética, ayes estaría en relación de intersección con calles: AyES $\cap$ cAllES

\section{TIPOLOGiA ${ }^{10}$}

La paronomasia puede ser estudiada bajo diversos puntos de vista. La primera distinción que cabe establecer se basa en la presencia o ausencia de los

9 V. epígrafe 4.3.

10 Se sigue, en general, la clasificación establecida por J.A. MARTiNEZ (1976). 
parónimos (paronomasia in praesentia/paronomasia in absentia). Otra diferenciación que puede hacerse atiende al carácter continuo o discontinuo con que se presentan los sonidos recurrentes (paronomasia continualparonomasia discontinua). Finalmente, se clasificará la paronomasia de acuerdo con el número de sonidos reiterados comunes a los términos puestos en relación y a su distribución dentro del segmento paronomásico (paronomasia de inclusión, de intersección y de exclusión). Al final de este trabajo se intenta dar una visión global de las diversas formas de manifestación del fenómeno, agrupando y combinando las distinciones hechas.

\subsection{Paronomasia in absentia/paronomasia in praesentia ${ }^{11}$}

La diferencia entre la paronomasia in praesentia (todos los ejemplos vistos hasta el momento) y la paronomasia in absentia consiste únicamente en que, en esta última, uno de los parónimos (a) no se halla presente en el texto, pero es anunciado indirectamente, connnotado, desde el plano del significado, por otro parónimo (a'), y, desde el plano del contenido, por otra palabra (z) ${ }^{12}$. Así, en:

184) «evitar» lo inhabitable

\section{(G. Fuertes)}

el elemento (a') -inhabitable-, desde el plano de la expresión, y el elemento (z) evitar-, desde el plano del contenido, connotan al parónimo esperable (a): inevitable.

Este tipo de paronomasia es fácilmente localizable en numerosas ocasiones gracias al carácter de expresión fijada o de mensaje literal ${ }^{13}$ de la construcción en la que aparece inserto:

185) «La cipresa está triste, ¿qué tendrá la cipresa?» [princesa

(G. Fuertes)

11 MartineZ, J.A. (1976), 79-81.

12 Se entrecomillan los presuntos «connotadores». Se utiliza el término hjelmsleviano de connotador en el sentido adoptado, entre otros, por JOHANSEN, Sv. (1949), «La notion de signe dans la glossématique et dans l'esthétique», Travaux du Cercle Linguistique de Copenhague, 5, 288-303, y por Salvador, G. (1964), «Análisis connotativo de un soneto de Unamuno», $A O, 14,18-39$.

13 LAZARo CARRETER, F. (1976), «El mensaje literal», en (1980), Estudios de lingüistica, Barcelona, Crítica, 149-171. Cf. con el concepto de discurso repetido según E. CoSERJU (1966), «Introducción al estudio estructural del léxico», en (1977), Principios de Semántica Estructural, Madrid, Gredos, 87-142 (esp. 113-8). Sobre su ruptura, v. esp. GARCfa PAGE, M. (1991), «A propósito de "La ruptura de un sistema formado por una frase hecha" ", $N E F, 6,71-101$, y la bibliografía allí citada. 
186) «Galerias Preciadas
[Preciados

(G. Fuertes)

187) Cantamos contigo [contamos

(G. Fuertes)

La paronomasia in absentia puede conseguirse por los procedimientos comunes ya indicados anteriormente: conmutación, adición o supresión e inversión.

a) Por conmutación:

189) Han hecho «pisos altos»

Enfrente de mi casa

existen rascainfiernos

[rascacielos

(G. Fuertes)

189) Las flores nunca pecaron.

Entre ellas mi «mano» almada [armada

dará su luz o su «muerte»

(M. Altolaguirre)

190) En este «dedo» indica si yo tuviera un ojo,...

[índice

(G. Fuertes)

191) Danzaban los «peces» debajo del alba

[agua

(G. Fuertes)

192) De golpe, «han muerto veintitrés millones» de cuerpos. Sobre dios "saltan de golpe» -sorda, sola «trinchera» de muertecon el alma en la mano, entre los dientes [arma

(B. de Otero) 
193) «arrastran con pujanza

el fardo» de los siglos

pasados

[pesados

\section{(Á. González)}

194) para que no se nos caiga el arma de vergüenza

[alma

(G. Fuertes)

195) Un come de invisibles «chicharras» [coro «chirria»...

(G. Fuertes)

196) porque el «pez» sin enagua

[el agua

(G. Fuertes)

196bis) ... no se forja así un poeta

para «hacerle la peseta»

[puñeta

(D. Alonso)

b) Por adición (o supresión):

197) sólo

Marte de "carnaval» [Martes

sórdido Eros de café cantante

(Á. González)

198) la «naranja» del Muerto

[huerto

(G. Fuertes)

199) ... como una amante «religiosa»

[mantis

(G. Fuertes)

200) como un «monje» solidario y solitario recito medio «rosario» de poesía y amor. «Ave" marina

[María

(G. Fuertes) 
201) He visto «hacerse» el «día» desnacerse la «noche» [deshacerse

$$
\text { (G. Fuertes) }
$$

202) que tu hermana la Luna se casa con el primo que llega Iprimero

$$
\text { (G. Fuertes) }
$$

203) Que te toque, oh poeta, mejor China y que un día veamos, Dios mediante, del Lupus «Dei» la atroz escabechina [Opus

$$
\text { (C. Álvarez) }
$$

204) «A mano» amada [armada cuando la noche impone su costumbre de insomnio (...) los recuerdos me «saltan»

\section{(Â. González)}

205) ¡Manos del «primer dían! ¡Deseos inexhaustos, [inexactos iberos devorados por los españoles! $Y$ pues que el deseo no tiene «medida» ni nombre conocido...

$$
\text { (G. Celaya) }
$$

c) Por permutación:

206) por puro «instinto» de conversación

$$
\text { [conservación }
$$

(G. Fuertes)

207) Todo te recordaba, Antonio Machado («andaba» yo igual que tú, de forma un poco vacilenta ${ }^{14}$ [vacilante

$$
\text { (B. de Otero) }
$$

14 Para otras posibles causas en la formación de esta voz, v. Garcla-PAGE, M. (1990), «Barbarismos. Algunos ejemplos de creaciones léxicas insólitas». BRAE, ej. 31), en prensa, y en H. A. Hernández (ed.), Teoría, Crítica e Historia Literaria, Cádiz, Universidad, 1992, 111-27. Sobre una posible acción de los metaplasmos por institución, vid. Grupo $\mu$, op. cit., cap. 2. Asimismo Garcta-PAGE, M. (1991), «Metagrafos en César Vallejo» (en prensa). 
208) formado de ciento «pelo» [terciopelo «suave al tacto»,,

(G. Fuertes)

209) Rubios, pulidos senos de Amaranta por una «lengua» de lebrel limados

[lamidos

(R. Alberti)

210) Porque la $\underline{\mathrm{ONU}}$ «o la Otra...»

[una-uno

(G. Fuertes)

\subsection{Paronomasia continua/Paronomasia discontinua}

De acuerdo con la distinción establecida por J. A. Martínez ${ }^{15}$, se obtiene a) una paronomasia continua cuando los «componentes del $\mathbf{s}$ (egmento) $\mathbf{p}$ (aronomásico) se suceden sin la interrupción de fonemas no reiterados»; igualmente, se consigue b) una paronomasia discontinua cuando «uno, varios o todos los sp se ven interrumpidos por fonemas alternantes, que no se reiteran». La paronomasia discontinua puede ser b.1) vocálica, si los fonemas alternantes son consonantes, y b.2) consonántica, si los fonemas alternantes son vocales. En virtud de esta última distinción, puede añadirse un tercer tipo de paronomasia discontinua, que se produce cuando b.3) la «discontinuidad» es, a la vez, vocálica y consonántica.

a) Paronomasia continua:

211) olVIDAs
que VIDA y muerte son tu obra

(J. Hierro)

212) tus pechos tan garridos remeMORÁndome de MORA

213) ¡SOLo la ola y el SOL!

(B. de Otero)

214) LIBA al niño su saLIVA

(J. R. Jiménez)

215) Y pregunto a la CIENCIA

(Casanova de Ayala) con paCIENCIA

(G. Fuertes)

15 MartíneZ, J.A. (1976), 76-8. 
216) Dejó el MAR al MARcharse

217) $\mathrm{ORQ}$ sonQRQ y fúlgido burila

(R. Alberti)

(M. Machado)

218) CALcinada de cólera

flatulenta de CAL

219) la baba del MAR aMARgo

(G. Fluertes)

(A. Machado)

220) Tierra desértica y aun con SOL deSOLada

(G. Fuertes)

221) (Adios, ramo florido de viLANos de LANa)

(R. Alberti)

222) S6́la en el árbol puesta, $\triangle A B E$ el AVE lo grata que es la sombra

223) LABIOS, sABIOS, Rosa loca

(M. Machado)

224) Si estuVIERAS aqui, si VIERAS hasta qué horas son cuatro estas paredes

(M. de Unamuno)

225) ...Pero bASTAn

las ASTAs del viento, los timones quietos hASTA hacerse uno

(M. de Unamuno)

b) Paronomasia discontinua:

b.1) Vocálica:

226) oasis de BELdAd a toda VELA

(M. Hernández)

227) luces ALLAS. ALAS de ángeles

(J. R. Jiménez)

228) Hijos del CIElO, CIEgOs en la arena

(R. Morales) 
229) te nace la CAlvA CAnA

(G. Fuertes)

230) esposas de AltoS CArgOS

CAlvOS

(G. Fuertes)

231) Entonces allí había la carrETERA EnTERA

(C.E. de Ory)

232) y aquella que las AIMAs AMAn

(L. Cernuda)

233) Sobre las aguas o TEjADOS puros consTEIADOS de fiesta

(L. Cernuda)

234) foNtAnar de la hONdA vida

(V. Aleixandre)

235) Quiero MUSlQs de acero, acaso MUSgQ tenue

(V. Aleixandre)

236) ¡Tanta VIdA que eVItA los siglos...!

(J. Hierro)

237) La tarde VIBrA como una gran mina VIVA

(J. R. Jiménez)

238) he DEVELADO

y me he DESVELADQ

(G. Fuertes)

239) El crepúsculo vomita PALiOs de 6PALO

(C. E. de Ory)

b.2.) Consonántica:

240) «El proyectil y su GORGaJO»

(buen trabajo)

Los GORGoJOs eran...

(G. Fuertes)

241) se escucha un GRiTO GROTesco

(M. Machado) 
242) MODiSTA porque coso rotos a la gente, MODeSTA, mi hijo es el silencio en zapatillas

(G. Fuertes)

243) son los LABiQs que aLABQ

(B. de Otero)

244) Las ovejas me BiSAN cuando PaSAN

(G. Fuertes)

245) todos estamos perdidos

PiCADOS por PeCADOS

(G. Fuertes)

246) los que CReCEn en el CRuCE de los muslos...

(F. García Lorca)

b.3) Vocálica + Consonántica:

247) No son PQeMAS, son PalOMAS

(G. Fuertes)

248) Jamás esCuCHA. Como ConchA vacía (L. Cernuda)

249) Mientras giran eternos, impasibles, los astros por un hELADQ cielo dEsoLADO y tranquilo

(R. Morales)

250) abyectas materias, mugre seca, jorra del seco MENDruGQ del MENDiGQ pobre

(G. Celaya)

251) Estoy sentado y huMEdeCIDO MECIDO por mis colores

(V. Aleixandre)

252) Junto a las bodegas donde el vino crece con TiBLAS manos TurBLAS, en silencio

(P. Neruda)

253) y el viento reza en los ramajes YerTOS LLanTOS de quenas, tímidos, inciertos (C. Vallejo)

254) Tortugueante la TORTUosA TORTUgA borrando sus huellas

(L. M. Panero) 
255) coger lApiCERO

y hACEROs un verso

(G. Fuertes)

256) REENCOTrARNOS

REENCanTARNOS

(G. Fuertes)

257) y espera un PASQ bien RiSAdQ

258) Nos hemos deVANadQ

(C. Rodríguez)

en VANO

(R. de Garciasol)

259) DESollADOS

DESamADOS

(G. Fuertes)

260) ¿PIenSAn? Nadie los PISA...

(J. R. Jiménez)

261) mientras que ACUos $A$ se $A C U n A$

(C. E. de Ory)

262) rueda de LOCOS COLOreS

(J. Hierro)

\subsection{Paronomasia de inclusión, de intersección, de exclusión}

Aunque J. A. Martínez establece una clasificación binaria ${ }^{16}$ entre paronomasia de inclusión -que se consigue cuando el «significante de "una" de las palabras coincide (es) un "sp" (= segmento paronomásico)»; p. e.: «con desmayo galán un guante de ante» (A. Machado)- y paronomasia de intersección que se obtiene cuando «ninguno de los "sp" es significante de palabra»; p. e.: «...exhalaba/un hombre y daba lumbre, lumbre y vida a una boca» (V. Aleixandre)-, puede proponerse, sin embargo, una nueva variedad que denominamos paronomasia de exclusión, que se consigue cuando los dos "sp" puestos en relación son significantes enteros de palabra. De acuerdo con esta definición, los parónimos se componen de los mismos fonemas, pero estos se hallan distribuidos en distinto orden posicional; p.e.: «Ya sé que soy tonta de amar tanto» (G. Fuertes). Por ello, en la paronomasia de «exclusión», sólo es posible la operación de permutación de los sonidos. La relación existente entre los vocablos re-

16 Idem, 75-6. 
lacionados por una paronomasia de exclusión viene a coincidir con lo que J.A. Martínez llama «inclusión recíproca» el describir la relación fónica entre los términos homofonos ${ }^{17}$ (antanaclasis).

\subsubsection{Paronomasia de inclusión}

El significante fónicamente menos extenso queda incluido en el parónimo más extenso: $\mathrm{B} \supset \mathrm{A}$ (A está incluido en B). Gráficamente:

$$
\text { gu ANTE }
$$

263) ¡Oh, liso POPE de ePOPEya y gallo (!)

(Casanova de Ayala)

264) Esgrime tu crESPADA

ESPADA, sobre verde

(M. Hernández)

265) Luego hay hombres de vidas apretadas a tu destino semidRRUIDO y muchachas que crecen entre el RUIDO

$$
\text { (Á. González) }
$$

266) Dame un trago de tu VINO ¡oh diVINQ Juan Ruiz!

(M. Machado)

267) Mi YERSO es para el uniYERSQ

$$
\text { (G. Fuertes) }
$$

268) en las hondas cAVERnas de donde el ARVE arranca su profundo sonido...

$$
\text { (L. Panero) }
$$

269) Junto al LADrillQ al LADQ, muy cercano

$$
\text { (C. Rodríguez) }
$$

${ }^{17}$ Ibidem, 86. Vid. además: MELAZzo, L. (1976), «Riflessioni linguistiche sulla figura rtorica dell' antanàclasi», Atti del X Congreso Internazionale di Studi, 125-130. 
270) Si fumo me fUMO hasta el hUMO

Si hABLO me escucha el diABLO

(C. E. de Ory)

271) que en el olvido puede calMAR el MAR sus olas

(R. Alberti)

272) con la aMARgura del MAR materna

(M. de Unamuno)

273) tierna amaZONA

tengo una ZONA

(G. Fuertes)

274) Me hiERES al mirar y no ERES ciego

(G. Fuertes)

275) tras el olivo, tréBoLE de la LEVE doncella

(B. de Otero)

276) ... hasta rebeldes piedras

que SÓLo el SOL de agosto logra hacer corazones

(M. Hernández)

\subsubsection{Paronomasia de intersección}

A y $B$ se hallan en relación de intersección cuando presentan un grupo de fonemas comunes y otro grupo de fonemas no recurrentes: $A \cap B$. Gráficamente:

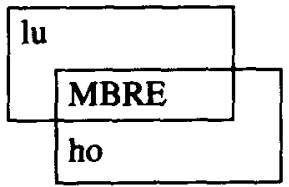

277) Los poetas, ningún ENCaNTO ENCueNTrO en ellos

(L. Cernuda)

278) y CASTOs CASTigarQn cuanto vieron (M. de Unamuno)

279) Cuando se sonrieron los CHAVALeS de las CHABoLAS (G. Fuertes) 
280) Princesa de mi infancia: tú PRincESA

PRomESA, con dos senos de clavel

(B. de Otero)

281) Los pianos golpean con sus colas enjambres de VIOLineS y de VIOLaS

$$
\text { (Á. González) }
$$

282) Tiene TERNuRA de TERNeRA

(G. Fuertes)

283) cambiadoras veletas, VELadorAS VELetAS

(J. Á. Valente)

284) Paraboile insecto CALenturiento CALa

(S. Ser si)

285) en CUalquiER CUERpo

(G. Fuertes)

286) ... andad en voz BAJa BAJo la pluma

(B. de Otero)

\subsubsection{Paronomasia de exclusión ${ }^{18}$}

A y B se excluyen: presentan los mismos fonemas pero en distinto orden combinatorio. Gráficamente:

TONTA $=$ TANTO o bien $\quad \begin{gathered}\mathrm{T} \\ \mathrm{A} \\ \mathrm{O}\end{gathered}$

287) en el bolsillo del ALMA

la MALA baba frailuna

(M. de Unamuno)

18 En la medida en que los parónimos presentan la misma constitución fonmética - aunque en distinto orden combinatorio- puede igualmente hablarse de paronomasia de kidentidadm. 
288) Yo soy un GATO, una GOTA de agua salada en tu Mano

(L. M. Panero)

289) Encinador antiguo de BACOS y de BOCAS

$$
\text { (Á. Crespo) }
$$

290) Yo de casarme hubiera SIDO con un DIOS

(G. Fuertes)

291) En tus callejas que del SON NOS guardan

(M. de Unamuno)

292) $Y$ un CLARO CALOR humano sube desde el fondo negro

(M. Hernández)

293) nos enseñaron a NADAR antes que a ANDAR

(G. Fuertes)

5. Como puede inferirse a partir de los ejemplos aducidos, las operaciones de conmutación, permutación y adición (o sustración) no son siempre compatibles con los tres tipos de paronomasias analizados en el epígrafe anterior. La paronomasia de inclusión implica necesariamente la adición de uno o varios constituyentes fónicos: en tanto que el significante entero de uno de los parónimos queda incluido en el otro parónimo, el parónimo fónicamente más extenso debe constituirse de, al menos, un sonido no repetido. Por ello, la paronomasia de inclusión implica necesariamente la ausencia de conmutación: «... la poesíal (es divina, repican las campanas)/ es un lujo, repLican los martillos» (B. de Otero). Los sonidos reiterados, no obstante, pueden aparecer en distinto orden combinatorio, por lo que la paronomasia de inclusión admite, no necesariamente, la operación de permutación: «Ya NoTo, al paso que me TorNo viejo» (A. Machado).

La paronomasia de intersección implica necesariamente o la adición (o sustracción) de un sonido: «Yo lo digo, yo lo sAnto,/yo lo cUEnto y tú lo veas» (G. A. Carriedo) o simplemente la conmutación de un sonido («mi ocio es leer/(...)/Mi color el azul/Mi cAlor tus brazos» (G. Fuertes). Adición y conmutación están en relación de complementariedad: en la paronomasia de intersección que se consigue por una operación de adición no es viable la operación de conmutación, en cuanto que la adición lleva implícita la conmutación; esto es, además de sustituirse un sonido, se añade, al menos, otro sonido: "yo quisiera haber sido deliNEante/o deliRante Safo sensitiva» (G. Fuertes). En este sentido, puede decirse que la paronomasia de intersección 
conseguida por una operación de adición implica necesariamente la ausencia de conmutación. Inversamente, si existe conmutación, no existe sustracción o adición de un sonido: "una luz me da en mi caRa, aquí, en mi caMa" (C. Rodríguez). Como en el caso de la paronomasia de inclusión, la paronomasia de intersección admite la posibilidad de que los sonidos se distribuyan en un orden invertido: «Se acortan, inservibles para el trAgo/de la entregA total al de la muerte» (R. Alberti).

La paronomasia de exclusión supone necesariamente la permutación de, al menos, un sonido, a la vez que la ausencia de adición y conmutación. En la medida en que, por definición, los parónimos se componen de los mismos sonidos (aunque en distinto orden distributivo), no pueden presentar ningún otro sonido no repetido: «-Perdón, Sereno, ¿cuál es el/bloque de en medIQ?/-El de todos los que tenemos mledo» (G. Fuertes).

La viabilidad de las formas de consecución (causas) en relación con los tres tipos de paronomasias podría resumirse de acuerdo con el gráfico siguiente:

\begin{tabular}{|l|c|c|c|}
\hline & Adición (Sustracción) & Conmutación & Permutación \\
\hline Inclusión & + & - & $(+)$ \\
\hline Intersección & {$[+]$} & {$[+]$} & $(+)$ \\
\hline Exclusión & - & - & $(+)$ \\
\hline
\end{tabular}

()$=$ opcional $\quad[]=$ complementariedad

6. Atendiendo al carácter continuo/discontinuo que presentan los segmentos paronomásicos, pueden señalarse las siguientes observaciones: la paronomasia de inclusión admite tanto la continuidad como la discontinuidad de los constituyentes fónicos: «cuyo sol solitario/alucinadamente/queme nuestros despojos» (J. Á. Valente); «Mujer casada,/cascada» (G. Fuertes). Los segmentos homofónicos de la paronomasia de intersección pueden presentar igualmente un carácter continuo o discontinuo: «... Cuán ceñido/es el abrazo de esa enorme horma/que no ahoga..." (V. Aleixandre); "Feto previvo/previsor del mañana» (G. Fuertes). Como puede inferirse, en las paronomasias de inclusión y de intersección, la continuidad y discontinuidad no pueden darse simultáneamente. La paronomasia de exclusión, por definición, implica necesariamente la 
continuidad en la sucesión de los sonidos conformantes: «la patria se hace celeste/limpiándose de su podre/de poder en su servidumbre» (M. de Unamuno).

Las observaciones indicadas pueden sintetizarse en el gráfico siguiente:

\begin{tabular}{|l|c|c|}
\hline & Continua & Discontinua \\
\hline Inclusión & {$[+]$} & {$[+]$} \\
\hline Intersección & {$[+]$} & {$[+]$} \\
\hline Exclusión & + & - \\
\hline
\end{tabular}

[ ] = Complementariedad

7. Entre las tres variedades vistas en 4.3 , existen casos límite, como puede verse en los siguientes ejemplos:

294) porque este aire de fuera no es mó, sino el cALIENTe ALIENTo

que si me acerco quema y dora mis labios

(V. Aleixandre)

295) cuando dos que no hablan el mismo amor se deTeCTAN y TaCTAN en un zarpazo

(G. Fuertes)

296) Apagando rescoldos que visLUMBRo

a la LUMBRe de la luz del alba

(G. Fuertes)

297) Soles distintos de DoRARON, maDURARON tu piel,...

(J. Hierro)

298) hUeSO de San FructUoSQ

(G. Fuertes)

299) A veces le enVIDIO sus ojos de YIDriO

(G. Fuertes) 
300) Me llamaban «POETA maldito» los PEOTAs del Café Gijon

(C.E. de Ory)

En los ejemplos 294)-299) se produce una falsa inclusión. En 300), lo que parece efectuarse es una paronomasia de exclusion. Sin embargo, en ambos casos se trata de meras manifestaciones de la paronomasia de intersección.

8. Frente a los estudios de retórica tradicionales que circunscriben el fenómenos de la paronomasia a los rígidos límites de la categoría palabra, es posible determinar un tipo particular de paronomasia que se obtiene cuando una unidad linguística entra en relación con dos o más palabras consecutivas de su contexto más próximo ${ }^{19}$ : «... sé que vienes/ a través de los siglos a mis venas,/atravesando corazones, penas...» (R. Morales); «... nunca saldré de esta aventura/lo que yo llamo la ventura mía» (C. E. de Ory): «ahora y en la hora/de nuestra muerte» (M. de Unamuno).

La paronomasia que excede los límites de la palabra puede presentarse bajo cualquiera de las formas de manifestación mencionadas (inclusión, etc.; continua, etc.).

a) Inclusión

301) La cometa del niño está piando junto a la tapia del cementerio

(B. de Otero)

302) el corazón que tengo en este lado

y el helado folleto de mi mente

(G. Fuertes)

b) Intersección

303) palideces de cera de enfrente

(G. Fuertes)

304) bajo el yugo $\sin$ fin del infinito

(M. de Unamuno)

19 Martinez, J.A. (1976), 74-5. 
c) Exclusión

305) y a España lo remonta, allí se cuela ¿formará escuela?

(M. de Unamuno)

306) A otros que, superiores a mi, esa ignorancia vuestra. Precipitó en la nada, como al gran Aldana.

(L. Cernuda)

d) Continua

307) Afán, afán, afán

Afavor de dulzura.

(J. Guillén)

308) que riega sus ecos

Vi llenos de humo los árboles secos.

(G. Fuertes)

e) Discontinua

309) ... mirándote

$\sin$ cansancio y con ansia

(J. R. Jiménez)

310) a mitra Domitila

(G. Fuertes)

Los procedimientos de consecución son también los mismos:

a) Por adición (o sustracción):

311) Primer pecado. - Reside en esto:

Hacer uso deshonesto

(G. Fuertes)

b) Por sustitucion:

312) y claro, me sale realista, y no porque sea lista

(G. Fuertes) 
c) Por permutación:

313) Yo, aquí, alerta,

al pie de laletra

$$
\text { (G. Fuertes) }
$$

Pueden citarse además otros ejemplos ilustrativos:

314) su metro de tejido que te dije

(C. Vallejo)

315) donde el mar el asco o la costumbre

(G. Fuertes)

316) A los 47 años de mi edad

da miedo decirlo...

(B. de Otero)

317) También tengo días buenos, días en que el hado está a mi lado

(G. Fuertes)

318) y para que me mire, haciendo memoria, a punto de sombríos...

(F. Grande)

319) Ahora es lahbora

(G. Fuertes)

Como puede observarse, este tipo de paronomasia se presenta como un fenómeno fronterizo con el calambur. Pero, mientras que el calambur puede definirse como el juego lingüístico en el que el significante entero de una palabra se presenta como la resultante $(\mathrm{AB})$ de combinar los significantes enteros de dos 0 más palabras inmediatamente consecutivas $(A+B)^{20}$; vgr.:

320) ... Ondulan silvestres. «Mira: flores».

Miraflores. La reina bautizó los cubiles.

(V. Aleixandre)

20 No obstante, en mi trabajo «Algunas observaciones acerca del calambur», Investigaciones Semíricas III, Madrid, UNED, 1990, vol. I, 431-48, propongo como posibles manifestaciones del calambur otros determinados fenómenos fronterizos con la paronomasia, en los que los términos del juego se suceden en un orden no consecutivo; p.e.: «Serafin Serafin será tu fin» (C.E. de Ory); «muerta en el frente de enfrente» (G. Fuertes); vgr.: A (serb/en) $+(. .)+.\mathrm{B}($ finffrente $)=\mathrm{AB}($ Serafin'enfrente). Cf. MARTtNEZ, J.A. (1976), 86-7. 
321) Ia que con vida convida

(G. Fuertes)

322) ¿Dije que se llamaba Marivi? Si, así se llamaba, viento y mary vi...

(B. de Otero)

323) Cuando la casa escasa sólo es casa

(G. Fuertes)

$$
\begin{aligned}
& A(\text { Mira })+B(\text { flores })=A B(\text { Miraflores }), A(\underline{\text { con }})+B(\text { vida })=A B(\text { convida }) \text {, } \\
& \text { etc. }
\end{aligned}
$$

En la parnomasia, los términos parónimos a) o no son significantes enteros de palabras $\left.\left(A^{\prime}+B+A B, A+B^{\prime}+A B, A^{\prime}+B^{\prime}+A B\right) o b\right)$ la resultante no es significante entero de palabra $\left(A+B=A^{\prime} B, A B^{\prime}, o A^{\prime} B^{\prime}\right)^{21}$. La notación $A^{\prime}, B^{\prime}$ o $A^{\prime} B, A B^{\prime}, A^{\prime} B$ ' representa la existencia de un sonido no recurrente. $S i$ $x$ representa el sonido no repetido, tenemos las siguientes igualdades: $A^{\prime}=A x$, $x A, x A x ; B^{\prime}=B x, x B, x B x$, etc. Para el caso a) pueden aducirse los siguiente ejemplos:

324) Lo dijo la vecina

- se avecina la garra de la guerra

$$
\text { (G. Fuertes) }
$$

325) La aventura de ver es la ventura

$$
\text { (L. Rosales) }
$$

326) - la rosa no interesa - la divina adivina primavera

$$
\text { (G. Fuertes) }
$$

327) Aquí yace Clarisa clara risa enclaustrada en la luz

$$
\text { (V. Huidoro) }
$$

21 El caso b) (ejemplos 329-331) es, sin duda, una de las formas de juego más difíciles de definir. Convencionalmente, pueden describirse como un tipo especial de calambur (o de pseudocalambur limitrofe con la paronomasia), tal como se hizo en GARCta-PAGE, M. (1988), La lengua..., 32-3 y 199-200, y especialmente en el cit. \&Algunas observaciones...». En este último trabajo pueden verse otros ejemplos que revelan el caracter fronterizo entre la paronomasia y el calambur. 
328) Te quise y aún te quiero todavia Toda vida te amé

(G. Fuertes)

$\mathrm{A}^{\prime}(\mathbf{l a})+\mathrm{B}($ vecina $)=\mathrm{AB}($ avecina $)$, donde $\mathrm{A}^{\prime}(\mathbf{l a})=\mathrm{x}(\mathbf{l}) \mathrm{A}(\underline{a}) ;$ etc.

Para el caso b), pueden aducirse ejemplos como los siguientes:

329) Me llega tu rumor atravesando troncos y ascensores, a trayés de láminas grises

(F. García Lorca)

330) No es cuestion de mi edad ni nimiedades

(G. Fuertes)

331) quedará esta mirada que pidio, y dio sin tiempo

(C. Rodríguez)

$\mathrm{A}(\mathrm{a})+\mathrm{B}($ través $)=\mathrm{AB}^{\prime}$ (atravesando), donde $\mathrm{B}^{\prime}($ travesando $)=\mathrm{B}($ través $) \times$ (ando), etc.

Puede además suceder $c$ ) que ni los elementos conformantes ni el término resultante sean significantes enteros de palabra: $A^{\prime}+B=(A B)^{\prime}, B^{\prime}+A=A^{\prime} B^{\prime}$, etc.

322) Mi espíritu es el casco de mi cáscara

y más caro me cuesta esta mi máscara

(C. E. de Ory)

333) No me lamas la mano. Me destruyo de gratitud y lejanía...

(R. de Garciasol)

334) Si te he visto no me acuerdo, me acuerdo y a cuerda no me gana nadie

(G. Fuertes)

335) y os perderéis sin ilusión, sin nada entre esta asesinada primavera

(R. Morales) 
336) esta palabra dice laboriosa

esta palabra dice labiorosa

(B. de Otero)

337) pararse en firme hasta que al cabo acabe

(M. de Unamuno)

$A($ más $)+B^{\prime}(\underline{c a r o})=A^{\prime}($ máscara $)$, etc.

De acuerdo con las observaciones hechas, pueden contrastarse en un mismo texto los fenómenos del calambur y la paronomasia:

338) fuíste un helecho (1)

El hecho (1) de haber sido helecho (2)

no condiciona al heche (2)

(G. Fuertes)

339) y tu chepita de mente (1)

era de menta (2) a ratos

y demente (1 y 2) a diario

(G. Fuertes)

(1) $\mathrm{A}($ (el) $)+\mathrm{B}($ hecho $)=\mathrm{AB}$ (helecho); (1) $\mathrm{A}$ (de) $+\mathrm{B}($ mente $)=\mathrm{AB}$ (demente)

(2) $\mathrm{A}^{\prime}(\mathrm{al})+\mathrm{B}$ (hecho) $=\mathrm{A}^{\prime} \mathrm{B}$ (helecho); (2) $\mathrm{A}$ (de) $+\mathrm{B}^{\prime}$ (menta) $=\mathrm{AB}$ (demente)

9. Como se ha podido observar, la paronomasia se presenta ocasionalmente como un fenómeno limítrofe con otros mecanismos lingüísticos (el calambur, el anagrama, la homofonía). Igualmente, pueden citarse ejemplos en los que la paromasia presenta concomitancias con otros «artificios» poéticos, como el parequema ${ }^{22}$ :

340) Por EIN, EINge la muerte un alba hermosa

(B. de Otero)

341) desde el NEYÁ NEVAdo hasta Pekín

(B. de Otero)

22 V., p. e. LAZARo CARRETER, F. (1953), s.v. parequema. 
342) y descubro que vivo de estar animal vivo y con otro aniMAL MALucho de ser mucho

(C.E. de Ory)

343) Esta CONSTA, CONSTAnte, en pie o hablando...

(V. Aleixandre)

344) - cuando venta el calor no habrá quien PARE-

PAREce ser que se quieren...

(G. Fuertes)

345) Tú ven, VEN

BENdito polen...

(C. Rodriguez)

346) Círculo en fuga, alJABA y JABAlina

(R, Alberti)

347) inTENTA TENTAtivas

(G. Fuertes)

348) ¡Cumbres del MAR MÁRmol del mar, espumas!

(R. Alberti)

349) Los andores verbales de la higuera, no alteran con sus iras mi gama de la frente: es SER SERena

(M. Hernández)

Como puede apreciarse, el efecto cacofónico que se produce simula en ocasiones una especie de tartamudeo silábico.

No siempre se produce una repetición exacta del grupo fónico:

350) pronunClaR CleBtas frases

(G. Fuertes)

Cuando el significante fónicamente más extenso precede inmediatamente al significante menos extenso, se obtiene una particular forma de inclusión cuyo efecto es semejante al que produce el eco. El término incluido reproduce el grupo fónico final del término incluyente:

351) Aqui yace AtAZOR AZOR fulminado por la altura

(V. Huidobro)

352) Los árboles en hilERA ERA un vapor inmóvil,...

(V. Aleixandre) 
353) pues para que las mALAS ALAS vuelen, aún quedan aires

(M. Hernández)

354) Nada de traBAJOS BAJOS. ¡Grandeza! ¡Y ostentación!

(G. Celaya)

355) Los reyes visigodos...

Sigerico... Alarico... Walia... TurisMUNDO

MUNDO de nombres...

(V. Aleixandre)

356) ... (No sé nada,

nada). GraNADA (no sé). NADA nada

éste es el sECO ECO de la sangre

(B. de Otero)

357) El alBA VA llegando entre las rosas

(R. Morales)

358) o bien en algún pueblo con paLOMAS

LOMAS y puente

(B. de Otero)

359) y por Archanda helECHOS hECHOS llanto

(B. de Otero)

360) a la deriVA YAn por la alameda

(R. Morales)

361) yo no escogí sino una SOLA OLA

(P. Neruda)

362) Con reflujos de plaTA.

ATA el ró y desata

(L. Cernuda)

363) ... Vámonos a la DehESA ESA...

(G. Fuertes)

364) como una matemática preESENCIA

ESENCIA terminante que resiste sin fin

(C. Bousono)

365) quiero oír cómo el pobre ruido de nuestro pulso se va a rasTRAS TRAS el cálido so nde esta alianza

(C. Rodríguez) 
366) ¡Elevadme, embeBEDME!

¿VEDME, resuciadme!

$$
\text { (C. Bousoño) }
$$

367) Y el mascarón que se disPARA

PARA

bailar en la procesion

(R. Alberti)

368) ... y para mí coca-cOLA ihOLA! ;Hola!

(B. de Otero)

En la mayoría de las ocasiones, lo que realmente se produce es una paronomasia de inclusión continua: "y deja entre las sombras más agudo/el blasfemar del mar contra las rocas» (R. de Garciasol); «y mezclados hoy nacen, hoy renacen, olvidan/vida mezclada a vida bajo la luz del cielo» (V. Aleixandre); «Señora, la hora tal vez importuna» (A. Machado), etc.

A veces, lo que se produce es un «falso» eco, en el sentido de que el parónimo fónicamente menos extenso presenta algún sonido no reiterado:

359) y en soledad se expresa queMADURa

MADURo el corazón por vía varia

(L. M. Panero)

370) Cándenos ceños, pasiones de luto, DIENTES seDIENTOS de ser colorados

(M. Hernández)

371) Los cindo largos dedos sabios amaNeCIAN. NaClAN probablemente para poner color en una mejilla...

(V. Aleixandre)

372) Barca vioLETA y LEnTA. Barca roja

(B. de Otero)

373) La luna está entre las ramas del ENEbRO

NEgRQ es el cuerpo del árbol

(L. Cernuda)

374) la brisa cabECEA cECEA, entre las hojas

(B. de Otero) 
No muy diferente es la relación que establece la paronomasia con la similicadencia (Homoioteleuton) ${ }^{23}$, figura en la que la semejanza fónica queda reducida al grupo final de palabra. La rima, perfecta o imperfecta, no es sino una variedad de similicadencia, con la particularidad de que, siendo una característica casi exclusivamente privativa del discurso en verso ${ }^{24}$, suele aparecer en las palabras finales de los versos conformantes de una estrofa; $v g r$. :

375) —o bajo la carpa del circo abandonado, tres atletas

$-\mathrm{mozO}, \mathrm{bOzO}, 1020$.

$$
\text { (L. M. Panero) }
$$

376) PaisAJE, celAJE, visAJE - tierra, cielo, rostro-

(M. de Unamuno)

377) ...los insectos, ocULTOS, sepULTOS, fuera de los insectos y dentro de mi carne

(Dámaso Alonso)

378) tos y lís...

(G. Fuertes)

379) que de la parda tierra Dios hilando

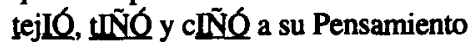

(M. de Unamuno)

380) ¡Tócame la viola de gAMBA, carAMBA!

(G. Fuertes)

23 Idem. s.v. Homeoteleuton.

24 No obstante, pueden exitir krima» en otro tipo de mensajes linguísticos, como p.e., en las paremias. Vid. GReIMAS, A.J. (1960), «Idiotismes, proverbes, dictons», Clex, 25, 2, 41 -61 (esp. 59); trabajo parcialmente recogido en Greimas, A.J. (1970), Du sens. Essais sémiotiques, París, Seuil, 309-314 (esp. 312), con el título: «Les proverbes et les distons». V. también LAzARo CARRETER, F. (1978), «Literatura y folklore: los refranes y (1979), «La lengua de los refranes. ¿Espontaneidad o artificio?», en (1980), Estudios..., op. cit., $207-217$ (esp. 214) y 219-239 (esp. 225-6) respectivamente.

En mi trabajo «Aspectos fónicos en la configuración de los refranes», Notas y Estudios Filológicos, 5 (1990), 75-121, especialmente \$ 3, 92-108 puede encontrarse un conjunto considerable de ejemplos relativos al factor rimante. V. además GARCIA-PAGE, M. (1990), «Propiedades lingüísticas del refrán (I)», Epos. Revista de Filología, 6, 499-510. 
No menos difícil es trazar una línea de delimitación entre la paronomasia y la aliteración, especialmente cuando son muy pocos los sonidos repetidos y estos pertenecen a palabras fónicamente poco extensas (p. e., monosílabos o bisílabos) ${ }^{25}$; vgr.:

381) para dar al SOn, al SQl, aire a la vela

(R. de Garciasol)

382) se oYEn aYEs de heridos entre el polvo

$$
\text { (J. Á. Valente) }
$$

383) El Río Ríe

$$
\text { (A. Machado) }
$$

384) donde canto la envidia maldice, RIE y RoE

$$
\text { (P. Neruda) }
$$

385) CRisto CReo en tu CRuz

$$
\text { (G. Fuertes) }
$$

386) ... Pido en mis actos y versos PAz, PAn, vino para todos los hombres de la Tierra

(R. de Garciasol).

Pueden compararse los ejemplos con los breves parequemas que se citan a continuación:

387) AL_alma se subió el árbol...

(E. Prados)

388) al borDE DEDEspertar

$$
\text { (G. Fuertes) }
$$

389) luego la gente NO NOta nada

(G. Fuertes)

390) los recibí en MI MIsma celda

(G. Fuertes)

391) y AL_ALba de tu hombro se acogía

(R. Morales)

25 Este aspecto ha sido también planteado por P. VALESIO (1967), Structture dell' alliterazione. Grammatica, retorica e folklore verbale, Bologna, Zanichelli, esp. 46-7. 
392) los campos SE SEcan solos

(G. Fuertes)

393) sale de LA oLA

(G. Fuertes)

Exceptuando acaso el fenómeno de la aliteración, puede decirse, en conclusión, que la paronomasia es un procedimiento más general, más amplio, que abarca otros mecanismos afines, desde el calambur hasta el parequema y el homoioteleuton. A estos habría que añadir también otros recursos de retórica, como la parequesis ${ }^{26}$ : «Ahora me preocupa no ocuparme» (G. Fuertes); «iOh, el dilecto/predilecto/de esta España que se agita» (A. Machado).

En relación con este último procedimiento, pueden verse algunos ejemplos de falsa etimología, que no son sino manifestaciones diversas de la paronomasia $^{27}$ :

394) Si canto soy un cantueso

Si leo soy un león

Si emano soy una mano

(C.E. de Ory)

395) Y el alma desalmada de su raza

(A. Machado)

396) quicio-resquicio por donde entro y salgo

(Á. González)

397) desde las sombras a las sombras asombrado de mi propio silencio

(L. M. Panero)

398) y más allá de torrenciales torres

(C. Vallejo)

399) adherencias sin numbo, herencias fras

(P. Neruda)

26 V., p. e.: LAZARO CARRETER, F. (1953), s.v. parequesis.

27 Semejante observación apunta R. SENABRE en (1966), «Juegos retóricos en la poesía de Blas de Oterow, Papeles de Son Armadans, 42, 125, 137-151, especialmente 139.

Puede apreciarse hasta que punto son factibles, en algunos casos, los morfemas derivativos: con - funde $=$ confunde, in - pacto $=$ impacto, araña $+-a d a+$ arañada, Cristo $+-a l=$ cristal, etc. 
400) para el pajaro azorado

para el sanguinario azor

(A. Machado)

401) por el sabio monosabio

(C. E. de Ory)

402) se funde y me confunde

(G. Fuertes)

403) el impacto y el pacto de la cruda intemperie

(L. Panero)

404) Piedras arrollas, tú el arroyo blanco

(C. E. de Ory)

405) penibélica pena

(C. E. de Ory)

406) Incunables tengo

hay cunas de niño...

(G. Fuertes)

407) arañada sin arañas

(G. Fuertes)

408) ¡Ay! (Por las torres aterradas) ¡Ay!

(R. Alberti)

409) Criste cristal purísimo

(G. Fuertes)

\section{Perceptibilidad. MeCanismos de apoyo}

Existen varios factores por los que la paronomasia puede ser percibida con mayor o menor rapidez y facilidad. El grado de intensidad dependerá, entre otras razones, de la mayor o menor proximidad entre los parónimos, del número de sonidos reiterativos que componen el segmento paronomásico en relación con el conjunto de sonidos no reiterados, de la forma de sucesión de los sonidos (continua/discontinua, linealidad/inversión, etc.).

a) La existencia de una serie de procedimientos constructivos puede acrecentar el grado de perceptibilidad del juego paronomásico. Si se tiene en cuenta 
que el poeta manipula constantemente el código lingüístico, la propia proximidad $^{28}$ sintáctica existente entre los parónimos puede considerarse como un auténtico artificio:

410) que musitas la dura cerrazón de los cielos, mientras mientes un agua que parece la sangre

\section{(V. Aleixandre)}

411) Penetran en una habitación, agolpada de sombras, hombres, vestidos

(V. Aleixandre)

412) desde las orillas de juncos junto a lagos, en sueños

(C. Bousoño)

413) me extrañé de no verla un instante antes, posándose generosa a mi lado...

(V. Aleixandre)

414) Aquí tuvo su fin el barro vano

(R. Morales)

415) que no se nos apaguen esos leños ileñe!

(G. Fuertes)

416) restos de autos y motocicletas, botes, botas, papeles y cartones

(R. Alberti)

417) -que la lava me encienda y la bravia brava te lave con la boca impia

(G. A. Carriedo)

28 Puede proponerse como otro mecanismo de apoyo el factor rimante.

La rima permite, sin embargo, relacionar palabras relativamente alejadas dentro de la estructura compositiva de un poema.

La rima puede tener un valor complementario como elemento de cohesión en ciertas construcciones más o menos fijas, como ocurre en las llamadas fórmulas rimadas, según la terminología de J. MORAWSKI (1927), «Les formules rimées de la langue espagnolem, $R F E, 14,113-33$. Así, puede observarse que la rima funciona sobre la memoria del lector a modo de fórmula mnemotécnica para que éste reconstruya la forma original a partir del binomio irreversible wamar a troche y noche» (es decir: a troche y moche), tal como indicamos en GARClA-PAGE, M. (1990), «Juegos lingüísticos en Gloria Fuertes (poesía)», RILCE, 6, 2, 211-43, especialmente 230-8. (Se emplea la expresión binomio irreversible en el sentido propuesto por Y. MAKIEl (1959), «Studies in irreversible binomials", Lingua, 8, 113-60). 
418) en los campos en donde incesantemente estallan extrañas flores encendidas

(Dámaso Alonso)

419) la dádiva el diván, la adivinanza

(G. A. Carriedo)

420) Por ventanas clavadas, grietas gritos, caricias

(P. García Baena)

421) Lo digo, y al decirlo, recuerdo cuentas, cuentos que Plinio registro con nombres sustanciales

(G. Celaya)

422) ...-En la pared sombras

de sapos van, una a una, pasando

Densando-no poder dejar de pensar

(L. M. Panero)

423) tresillos, visillos

(G. Fuertes)

424) a aquel mundo perdido

donde hubo tante cante

(P. Salinas)

425) esta enfermita de termita

(G. Fuertes)

426) de conceptos e ideas, de poúmenos fenómenos

(M. de Unamuno)

427) átboles abolidos

(B. de Otero)

428) ... barcas blancas

habrán llegado a verse

(J. Hierro)

429) la espada

(espaldas

antiguas sollozan entre las ramas

(L. M. Panero)

430) la tigrata ingrata

(G. Fuertes) 
431) Pájanos. Párpados.

Se posa

apenas la pupila

en la ostentada luz

(J. A. Valente)

432) ...horrisono sonido

dónde

se esconde

(C. Bousoño)

433) ponte el leotardo petardo

(G. Fuertes)

b) Los parónimos pueden agruparse por coordinacion:

434) orar y lorar fue mi oficio

(C.E. de Ory)

435) ... y me emociono

disimulando ciencia e inocencia

(C. Rodriguez)

436) Rima y razón, color y olor tal rosa

(L. Cemuda)

437) como un largo túnel de trajes y trabajos

(P. Neruda)

438) ... tan sencilla

y temerosa y misteriosa y nueva, y siempre

(C. Rodríguez)

439) Aquí lo afirmo y firma con mi nombre

(R. Alberti)

440) ... con ramos que se exhalan

en olor y color bajo un cielo perpetuo

(V. Aleixandre)

441) mas de gran cantidad de trige y trine

(C. Rodríguez)

442) Dejo hijos y hojas de papel mal rellenos

(C. E. de Ory) 
443) cosas de ayer que sois al alma, y cantos y cuentos de la abuela

(A. Machado)

444) Todos los aceites del mundo, los oleosos minerales como una sangre circulan y se asoman y espiran, y respiran y callan

(V. Aleixandre)

445) Yentura y aventura sin fin. Lope aquí ardiendo

(V. Aleixandre)

446) sobre una visión ciega, pero cierta

$$
\text { (J. Á. Valente) }
$$

447) las mil varias cacatúas y caricaturas a todo color

(G. Celaya)

448) ... y violáceas plantas carnívoras

habitan el triángulo falídico o fatídico

(G. Fuertes)

449) Es, Teresa, tu nombre, misterio y martinio

(M. de Unamuno)

450) En la casa desierta o desertada

(J. Á. Valente)

451) Vasos o besos, luces o escaleras

(V. Aleixandre)

452) Y lo afirma y firma un poeta
(G. Fuertes)

453) el personaje blanco llora y ora

M. Machado)

454) (lleno de libros y libras)

(G. Fuertes)

455) verdes sierpes ya trémulas de roces y rocios...

(M. Hernández)

456) Yiviera y escribiera como escribo

(B. de Otero) 
457) Fuerza febril, felina y femenina

(L. Cemuda)

458) Evitar supotancios y soponcios

(G. Fuertes)

459) Canto y cuento es la poesía

(A. Machado)

460) Violencia constante estéril del vegetativo y vengativo callado sedentario loco

(C. E. de Ory)

461) Mientras ella ligera se exime, adorada y dorada

(V. Aleixandre)

462) ... Sevilla está llena de sol y sal

(M. Machado)

463) ... harán tus glorias palidecer y parecer pequeño tu asiento...

(L. Panero)

464) ... este planeta lleno de piel y piedras

(P. Neruda)

465) Noche de Renacimiento y Remordimiento

(C. E. de Ory)

c) Los parónimos se sitúan en el mismo lugar de una estructura sintagmática repetida:

466) tiempo de odiar y tiempo de adorar

(R. Molina)

467) tanto guante $y$ tanto aguante

(G. Fuertes)

468) entre todos los muertos y todos los muñecos

(C. E. de Ory) 
469) dejando allí, en alcobas tan fecundas, su poso y su despojo

(C. Rodriguez)

470) Gritaron: ¡a las umas!

y él entendio: ¡a las armas!...
(Á. González)

471) La cáscara y la máscara, los cuarteles, los foros y los claustros

$$
\text { (C. Rodríguez) }
$$

472) ¿No será esta noche del balance, noche de la balanza donde arrojes tus días(?)

(P. García Baena)

473) cara a cara el infierno de los ojos sellados, de los ojos cerrados para siempre...

$$
\text { (L. M. Panero) }
$$

474) Tan serena, tan severa, Madre Muerte

(G. Celaya)

475) llenando a Dios de oprobios y de agravios

$$
\text { (C. E. de Ory) }
$$

476) la luz me da en mi cara, aquí, en mi cama

$$
\text { (C. Rodríguez) }
$$

477) mientras la tarde en su jardín me encierra y me incendia y abrasa con sus párpados

$$
\text { (R. Molina) }
$$

478) ¿Qué olor y que dolor de flores amarillas (!)

$$
\text { (J. R. Jiménez) }
$$

479) El hombre y sed. Más ser, más sed. La sed o ser, o sed de ser... (V. Aleixandre)

480) Entre lo ético y lo pośtico

$$
\text { (G. Fuertes) }
$$

481) Las olas rompen y me embisten y me visten de blancas yedras

$$
\text { (J. Hierro) }
$$

482) Aunque no nos movamos nos yamos acercando vertiginosamente (G. Fuertes) 
483) ... se posa

sobre tu pecho y te reluce a grano,

a grumo, a gota cereal, el pájaro

(J. Á. Valente)

484) JPero abajo hay yoces,

hay roces. ¿Quién llama?

(V. Aleixandre)

485) y está hecho ya polvo con el polvo

de la trilla y de la tralla

(G. Fuertes)

486) ... ¿El río mana

del cielo o de la nube? El río hermana

de todo - nada con la nada - todo

(M. de Unamuno)

487) Pero el hombre y el hambre

me dolían todos los días

(G. Fuertes)

488) Como una abeja rubia gime el aire y me ronda y me rueda, y yo no alcanzo

(F. Brines)

489) Hay madrugadas que no sé si al levantrme de la mesa ir al lecho ¡o irme a la leche!

(G. Fuertes)

490) que entre sandeces, sin pasion, te pega y te paga después con un gazpacho

(M. de Unamuno)

d) Los parónimos son componentes de estructuras sintácticas simétricas ${ }^{29}$ :

491) la cuña de los años, la coña de los cantos

(G. Celaya)

29 Para el concepto de simetria, vid. Alonso, D. (1955), «La simetría bilateral», en Estudios..., o.c., 117-73. Vid. también del mismo autor (1950), Poesía española. Ensayo de métodos y límites estillisticos, Madrid, Gredos, ${ }^{5} 1981$, y, en colaboración con C. Bousono, Seis calas en la ex- 
492) ... Oh altos

homos, infiernos hondos en la niebla

(B. de Otero)

493) ojo de la ruina, rebojo de la gloria

(M. de Unamuno)

494) Carta meto, mosca mato

(Casanova de Ayala)

495) apaga mi poder y propaga mi duelo

(P. Neruda)

496) está seco, sus ramas sin hojas,

su tronco $\sin$ ojos

(G. Fuertes)

e) Estas estructuras simétricas pueden distribuirse en versos paralelísticos:

- Al comienzo (anáfora):

497) cúmule de sierpes

túmulo de lava

(G. Fuertes)

presión literaria española, Madrid, Gredos, ${ }^{4} 1979$ (1." ed., 1951). Puede contrastarse con el trabajo de M. SHAPIRo (1976), Asymetry. An inquiry into the linguistic structure of poetry, Amsterdam, North-Holland Publishing Company.

Sobre el paralelismo, pueden consultarse igualmente los trabajos, entre otros: JAKOBSON, $\mathbf{R}$. (1960), «Linguística y poética», Ensayos de lingüistica general (1963), Barcelona, Ariel, 1984, 7994 y (1966), «Le parallelisme grammatical et ses aspects russes», Questions de poétique, París, Seuil, 1973, 234-79; LEVIN, S.R. (1962), Estructuras lingüisticas en la poesía. Madrid, Cátedra, 1974; RUWET, N. (1974), «Parallélismes et déviations en poèsie», en RUWET, N. y otros (eds.), Langage, discours, societé. Pour Émile Benveniste, París, Seuil, 1975, 307-51; ChMÉlev, D. (1970), «Le parallélisme asymétrique dans la langue poétique», en GrIGORIEv, V. (ed.) (1981), Linguistique et poétique, Moscú, Progrés, 192-202; MoLINo, J. (1981), «Sur le parallélisme morphosyntaxique», LFr, 49, 77-91; MOLINO, J.-TAIME, J. (1982), «REpétitions et parallélismes», Introduction à l'analyse linguistique de la poèsie, París, PUF, cap. 5, 184-226; FréDERIC, M. (1985), La répétition. Etude linguistique et rhétorique, Tubinga, Max Niemeyer Verlag; GARCta-PAGE, M. (1992), «Precisiones terminológicas en retórica (I): Figuras de repetición lingüístican, $N E F, 7,161-77$; etc. Algunas aplicaciones pueden verse en: ATKINSON, D.M. (1953), «Los cantares paralelísticos castellanos. Tradición y originalidad», RFE, 37, 129-67; MUNIZ, A. (1961), «El paralelismo en la lírica popular mexicanam, AdL, 1, 149-70; AlvaR, M. (1971), Cantos de boda judeoespañoles, Madrid, I. Arias Montano, cap. 6; etc. 
498) tormenta para hundiros

tormento para desesperaros

$$
\text { (G. Fuertes) }
$$

499) Bebo y me sabe todo a llanto tuyo

Bese y me sabe a nada no es tu boca

(G. Fuertes)

500) Sal de mi tierra, sol de mi cielo

(M. de Unamuno)

- A la mitad del verso:

501) entre el hombre y su rostro entre el nombre de Dios y su vacío

$$
\text { (J. A. Valente) }
$$

502) Nos separa una vida de color del desierto Nos espera una historia de sollozos y gozos

(C. E. De Ory)

503) todo el color fluyente de la seda gozosa, todo el claror hermoso de su abril fugitivo

(R. Morales)

504) las piruetas de un papel de estraza, las siluetas de las servilletas de papel de seda

$$
\text { (J. A. Valente) }
$$

505) me convence en silencio me convierte en paloma

(G. Fuertes)

506) en el verano piso por la playa en el otoño plise los visillos

(G. Fuertes)

507) el canto a la moza y el cuento a la abuela

(A. Machado)

508) Cuando el parquet se hunda, cuando el por qué se rompe

(G. Fuertes) 
- Al final (epifora):

509) me preguntan los hombres con los ojos. las madres me preguntan con sus hijos, los árboles me insisten con sus hojas

(G. Fuertes)

510) y a enderezar entuertos y a embellecer a tuertas

(G. Fuertes)

511) Si sola, pensad que hubo otras mujeres que las véis, otros hombres, otros nombres para decir y cantar

(R. de Garciasol)

512) Pierdes la chaqueta cambias la chaveta

(G. Fuertes)

513) amante sin olas octano sin alas

(G. Fuertes)

514) La soltera nace

La solterona se hace

(G. Fuertes)

515) a pulso,

a pelo,

a palo seco

(G. Fuertes)

f) El juego paronomásico puede quedar intensificado si, además de reiterarse la misma $\multimap$ aparentemente la misma - pauta sintáctica, se repiten todos $o$ casi todos los constituyentes léxicos y gramaticales:

516) que también aspirase, que tambien esperase (V. Aleixandre)

517) me desperté para cantar al viento, para cantar el yerso

(Dámaso Alonso) 
518) Quedan las cartas. Quema las cartas.

(P. García Baena)

519) Brillan mis manos en la losa.

Brillan mis manos en la fosa.

(C. E. de Ory)

520) Canten tus alas, canten tus olas

(R. Alberti)

521) Arbol, ¿qué pasa con tus hojas?

Aire, ¿qué pasa con mis ojos?

(G. Fuertes)

522) ¿Vienes a por los hijos de tu mesa?

¿Vienes a por las frutas de tu misa?

(C.E. de Ory)

523) me pegan y escribo

me pagan y escribo

(G. Fuertes)

524) estamos hechos trozos,

estamos hechos trizas

(G. Fuertes)

525) Que en los penales no haya ningún justo; que en los panales no haya ningún zángano.

Que en las trazas no haya hipocresía

que en los trece no haya desengaño

(G. Fuertes)

526) Creo en los platillos volantes

Creo en las platillas que envuelven el chocolate

(G. Fuertes)

g) Los parónimos pueden concatenarse simulando un fenómeno de reduplicación. En algunos ejemplos, lo que parece que se pretende es corregir o precisar una expresión (epanortosis) ${ }^{30}$ :

527) ... Porque el pueblo se ha cansado de parecer tonto

$\rightarrow$ de padecer tanto

(G. Fuertes)

30 Vid. LAZARO CARRETER, F. (1953), op. cit., s.v. eparnortosis. 
528) abora que no te tengo, que no te temo; muerto aquellos días...

\section{(P. García Baena)}

529) ... y vengo yocenado, buceando, mejor, entre la niebla

(G. Fuertes)

531) dentro y abajo el corazón latidor, el corazón relatador lque contase...

\section{(V. Aleixandre)}

532) y humos lentos velaron, vedaron el castillo, nívea cárcel

$$
\text { (R. Alberti) }
$$

533) ¡Ay qué lucha, digo qué lechẹ!

(G. Fuertes)

534) Pero suenan, sueñan

hacia adelante campanas festeras

$$
\text { (R. de Garciasol) }
$$

535) inmoviles, idiotas parecemos. perecemos de sed bebiendo vino

(G. Fuertes)

536) En ella se encierra - se entierrauna pobre pareja de abuelos

(M. de Unamuno)

537) y las tres restantes para, para parar con bordones

(G. Fuertes)

h) El juego lingüístico será aún más intenso cuantos más constituyentes léxicos entre en relación paronomásica. Así, pueden combinarse diversas variedades de paronomasia (inclusión + intersección, etc.):

538) mientras el amante recién engendrado entra en el cuerpo de la mujer madre

$$
\text { (J. Á. Valente) }
$$


539) donde resbalan leves las silenciosas aves

(V. Aleixandre)

540) empieza

a brotar yerdes, aves tan diversas

(R. de Garciasol)

541) yo veía el poderoso sol lentamente monderle con mucho amor y adormirle

(V. Aleixandre)

542) En estas tardes pardas mientras tardas las horas resbalando

(M. de Unamuno)

543) manada de algún duende nigromante peinaré de mi espalda el monte amante

(C. E. de Ory)

544) Al hombro. Lo arrojé). Me junté al hombre, ... en nombre

de la imperecedera juventud

(B. de Otero)

545) considera tu crisis, sume, sigue, tajala, bajiala, Gjala

(C. Vallejo)

546) Alada brisa salada

brasa viva

(R. Alberti)

547) aves suaves, lluvias, hilos, llaves

(C. E. de Ory)

548) su tallo, su verde talle

¡Con las estrellas mías (!)

(R. Alberti)

549) amarga mar de Málaga

(B. de Otero)

550) ... después de tanta luz, de tanto tacte sutil, de Tántalo es la pena

(B. de Otero) 

551) pacem
en latín
pas pasa pan
con chocolate

(Á. González)

A veces, puede determinarse un caso de doble, o múltiple, inclusión:

552) se acuesta una muchacha encuadernada

en piel de cielo que es de terciopelo

(C. E. de Ory)

$\left.\mid \begin{array}{l}\text { pelo } \\ \text { cielo }\end{array}\right\} \subset\{$ terciopelo $\}$

553) Era la pena de la petenera

(P. García Baena)

$\left|\begin{array}{l}\text { era } \\ \text { pena }\end{array}\right| \subset$ \{petenera

554) han anudado al fin este cuerpo a la nada en ella nado

(L. M. Panero)

$\left|\begin{array}{l}\text { nada } \\ \text { nado }\end{array}\right| \subset\{$ anudado $\}$

555) pobres probetas si no tenéis más que los poetas

(G. Fuertes)

$\left(\begin{array}{l}\text { pobres } \\ \text { poetas }\end{array}\right\} \subset\{$ probetas $\}$

556) se reíen de la inocencia, han hecho del puro amor una indecencia.

¡No sé qué coño hace la ciencia!

A los no locos se nos acaba la pila de la paciencia

(G. Fuertes)

$$
\left\{\text { ciencia } \subset \subset\left\{\begin{array}{l}
\mathrm{i}(\mathrm{no}) \text { cencia } \\
\mathrm{i}(\mathrm{nde}) \mathrm{cencia} \\
(\mathrm{pa}) \text { ciencia }
\end{array}\right)\right.
$$


557) ...Clamamos

a Ti, Cristo Jesús, desde la sima

de nuestro abismo de miseria humana

(M. de Unamuno)

$\{$ sima $\} \subset\left\{\begin{array}{l}\text { a(b)ism(o) } \\ \text { mis(eri)a }\end{array}\right\}$

558) Amante de diamante mi hija hambrienta

(C. E. de Ory)

\{amante $\} \subset\left|\begin{array}{l}\text { (di)amante } \\ \text { ham(bri)enta }\end{array}\right|$

559) Nefanda, ponte la bufanda y anda

(G. Fuertes)

$\{$ anda $\} \subset\left\{\begin{array}{l}\text { (buf)anda } \\ \text { (nef)anda }\end{array} \mid\right.$

560) Acelerado aire era mi sueño

por las aparecidas esperanzas

(R. Alberti)

$$
\{\text { era }\} \subset\left\{\begin{array}{l}
(\text { acel)era(do) } \\
\text { a(i)re } \\
\text { (ap)are(cidas) } \\
\text { (esp)era(nzas) }
\end{array}\right\}
$$

Puede igualmente producirse una doble, o múltiple, relación de interesección:

561) ... por el valle

Donde velan yerdes lebreles místicos, los chopos

(L. Cernuda)

va(lle) $\cap$ ve(l)a

$\operatorname{vel}(a n) \cap$ leb(reles)

ver(d)es $\cap$ (le)bre(l)es 
562) ¡Oh espeso manto de ardiente aliento asciende!

(E. Prados)

$$
\begin{aligned}
& \mathrm{a}(\mathrm{sc}) \operatorname{ien}(\mathrm{d}) \mathrm{e} \cap \mathrm{a}(\mathrm{rd}) \text { ien(t)e } \\
& \mathrm{a}(\mathrm{l}) \operatorname{ient}(\mathrm{o}) \cap \mathrm{a}(\mathrm{rd}) \operatorname{ient}(\mathrm{e})
\end{aligned}
$$

En otras ocasiones, llega a establecerse un particular paralelismo entre dos juegos paronomásicos distintos:

563) para todas las cintas más distantes para todas las citas más distintas

$$
\text { (C. Vallejo) }
$$

cintas-citas // distantes-distintas

564) Importa que el otoño se inierte en los otoños importa que el otoño se integre de retoños

$$
\text { (C. Vallejo) }
$$

injerte-integre // otoños-retoños

565) -la oveja vale si bala-

-la abeja yale si vuela

(G. Fuertes)

oveja-abeja // bala-vuela-vale

566) Con el alma al hombro

bajo un elme, el hombre

(G. Fuertes)

alma-olmo // hombre-hombro

567) con mi constante pena instante, plena

(M. Hernández)

constante-instante // pena-plena

568) si las sulabas yalen

si las sibila acierta

(G. Fuertes)

$\mathrm{si}+\mathrm{las}+\mathrm{va}(\mathrm{len})=\mathrm{s}(\mathrm{abas} / \mathrm{si}+\mathrm{la}=\mathrm{si}(\mathrm{bi}) \mathrm{la}$ 
i) Debido a la pertinencia fonológica del acento en español, palabras fonemáticamente muy afines se perciben más difícilmente por la diferente posición que adopta el acento en las mismas; vgr.:

569) Cuelga de una ventana con nubes su casaca, la ćáscara de su manto cotidiano

(J. Hierro)

570) Remonto entre tus paginas pajizas el curso de mi vida...

(M. de Unamuno)

571) para que la USA no la vuela a usar

(G. Fuertes)

572) iLaude a laúd, sonora luz del alba (!)

(R. Alberti)

573) Más leve, más esbelto, más sedoso ¿qué lirio? En el plano lírice como un adiós distante...

(J. R. Jiménez)

574) y otro pajaro estaba en el pajar

(G. Fuertes)

575) árbol sin sabor a árbol

(R. Alberti)

11. EFECTOS:

El carácter lúdico del fenómeno de la paronomasia puede apreciarse de modo especial en determinados ejemplos en los que adopta una configuración particular.

a) Incrementación progresiva: El segmento paronomásico de una palabra va incorporando, de manera progresiva, nuevos constituyentes fónicos en cada uno de los parónimos que se ponen en relación:

576) cuando te aunaba entre las olas solas

(C. Bousoño)

las $\rightarrow$ olas $\rightarrow$ solas 
577) te daria calor

te adoraria.

Harra

algo que es más difícil

(J. Hierro)

haria $\rightarrow$ dana $\rightarrow$ adoraria

578) En luz malva y errante

que da su son al alba

(J. Hierro)

al $\rightarrow$ alba $\rightarrow$ malva

579) sin ciencia, en inocencia, en inconciencia

(M. de Unamuno)

ciencia $\rightarrow$ inocencia $\rightarrow$ inconciencia

580) Bajo las blancas alas de tus manos

(M. de Unamuno)

las $\rightarrow$ alas $\rightarrow$ blancas

581) y los navarros en Soria que alli plantaron su Narros

y Naharros en Valdunciel...

(G. Celaya)

Narros $\rightarrow$ Naharros $\rightarrow$ Navarros

582) los cuerpos de deseo, de sed de alcohol, de angustia por las tardes

(Á. González)

de $\rightarrow$ sed $\rightarrow$ deseo

583) en el mar, como un himen inmenso,

mecen los árboles el silencio verde

(B. de Otero)

me(ce)n $\rightarrow$ himen $\rightarrow$ inmenso

584) ¿A dónde ibas tú pelota de pelo pedazo de oro... (?)

(G. Fuertes)

pe(dazo) $\rightarrow$ pelo $\rightarrow$ pelota 
585) Y vivamos que de nada somos amos yamos yamos no hablemos de dinero

(C. E. de Ory)

(so)mos $\rightarrow$ amos $\rightarrow$ vamos $\rightarrow$ viyamos

586) Dime que me destrimide y me arrime

(G. A. Carriedo)

me $\rightarrow$ (arr)ime $\rightarrow$ dime $\rightarrow$ destímide

587) Mi nostalgia del mar sube

amarga de espuma y sal

(E. Prados)

(espu)ma $\rightarrow$ mar $\rightarrow$ amarga

588) en el desierto ese del deseo

(G. Fuertes)

ese $\rightarrow$ deseo $\rightarrow$ desierto

589) la forma suprema del amo

(L. Cernuda)

(sup)r(e)ma $\rightarrow$ amor $\rightarrow$ forma

590) mirar de milenario y de marino

(C. E. de Ory)

$\operatorname{mira}(r) \rightarrow$ marino $\rightarrow$ milenario

591) Ya la lava

va balada a tus pies...

(G. Fuertes)

la $+\mathrm{va} \rightarrow$ lava $\rightarrow$ balada

592) porque sf, porque es sine

y siene y simulacro

(C. Bousoño)

si $\rightarrow$ sino $\rightarrow$ signe 
593) un color, un olor, y una flor

(C. Bousoño)

(f)lor $\rightarrow$ olor $\rightarrow$ color

594) esa honesta

testa que detestaba el pensamiento

(Á. González)

esa $\rightarrow$ (hon)esta $\rightarrow$ testa $\rightarrow$ detestaba

595) date el bote con estrambote

(G. Fuertes)

(da)te $\rightarrow$ bote $\rightarrow$ estrambote

b) Suma: La combinación de dos significantes $(\mathrm{a}, \mathrm{b})$, previa eliminación de los sonidos no recurrentes, da lugar a un nuevo significante (c):

596) qué olores colores, sabores, contactos...?

(J. Hierro)

$\mathrm{qu}(\hat{e})+$ olores $=$ colores

597) en esta noche hay algdo de navios de camaval de Navidad de Nayacerrada

de came y yendabal noche de noches

(C. E. de Ory)

$\operatorname{carn}(\mathrm{e})+($ vend $)$ aval $=$ carnaval

598) ¿Qué pasa en este mundo donde me hundo?

(G. Fuertes)

$\mathrm{m}(\mathrm{e})+$ hundo $=$ mundo

599) porque alta eres y estaras en altares

(G. Fuertes)

alta $+(\mathbf{e})$ res $=$ altares 
600) $Y$ van las horas, mas no van en vano

(M. de Unamuno)

$\mathrm{va}(\mathrm{n})+\mathrm{no}=\mathrm{vano}$

601) Aqui yace Rosario rí de rosas hasta el infinito Aqui yace Raimunde raíces del mundo son sus venas Aquí yace Clarisa clara risa enclaustrada en la luz Aquí yace Alejandro antro alejado ala adentro (...)

(V. Huidobro)

rosa $(s)+$ roo $=$ Rosario

$\operatorname{rar}($ ces $)+$ mundo $=$ Raimundo

clar(a) + r(isa) $=$ Clarisa

aleja $(a) d(o)+$ an $(t) r o=$ Alejandro

602) entre las uñas tierra en las entrañas

(G. Fuertes)

entr(e) $+(1) a(s)+(u)$ naas $=$ entrañas

603) al tocar lo que amas te quemas

(G. Fuertes)

que $+(\mathrm{a})$ mas $=$ quemas

604) si los senos son olas, si son remos

los brazos, si son alas solas de oro...

(B. de Otero)

so(n) $+(a) l a s=$ solas

605) Entre Santander y Asturias

pasa un río, pasa un ciervo,

pasa un rebaño de santas

(G. Fuertes)

Sant (ander) + As(turias $)=$ santas

606) Vas y vienes

y yo sierra

que te sierra

los arbustos

de mis sienes

(G. Fuertes)

sie $($ rra $)+($ vie $)$ nes $=$ sienes 
607)
la Toca
la vida todavía

(J. Hierro)

to(c)a + vida + todavía

608) ¿Son lascas de la luna, alas acase

llovidas al azar... (?)

(R. Alberti)

(a)las $+($ a) $\operatorname{cas}(0)=$ lascas

Como puede comprobarse, en algunos casos es necesaria la reordenación de los distintos fonemas conformantes del término (c). guiente:

Estos ejemplos se distinguen de juegos paronomásicos como el si-

609) Salgo corriendo atolondrada

loca

y tropiezo con Dios

- ¿Dónde vas Leocadia? - así suele llamarse

(G. Fuertes)

loca + Di(os $)=\mathrm{L}(\mathrm{e})$ ocadi $(\mathrm{a})$

c) Sincopación: Dos o más palabras difieren entre sí por la presencia/ausencia de uno o varios sonidos mediales no recurrentes:

610) veo en tu yerbo, creo...

(R. de Garciasol)

$v e(t b) o=v e o$

611) ... Es el circule del circo

(F. Brines)

círc(ul)o $=$ circo

612) ¡Corre, ve, viento marere,

y dile a algún marinere

que el faro no está encendido!

(R. Alberti)

$\operatorname{mar}($ in $)$ ero $=$ marero 
613) seres serpientes del Museo del Mal

(C. E. de Ory)

ser(pient)es $=$ seres

614) lamente lento

(P. Neruda)

I(am)ento $=$ lento

615) Eotografa fofa

(G. Fuertes)

fo(tógra)fa $=$ fofa

616) llegará un momento

que será sin escultor un monumente

(G. Fuertes)

$\operatorname{mo}(\mathrm{nu}) \operatorname{mento}=$ momento

617) tú, subiendo mis locas escalas y escaleras

(P. Neruda)

escal(er)as $=$ escalas

d) Falsa etimología: Los parónimos simulan ser palabras pertenecientes a una misma «familia» de palabras:

618) sus versos y sus reversos

(G. Celaya)

619) copian comucopias

(M. Machado)

620) (en la gloria del sexo y el amor de los amantes moraban demoraban)

$$
\text { (F. Brines) }
$$

621) Su violín violeta con su violín violáceo con su violín violado

(V. Huidobro) 
622) con que Dios bendito nos venda al mirar

(M. de Unamuno)

623) de quien no tenga llave

para abrirse las venas venerables

(R. de Garciasol)

624) la piel que sobraba sobre su cuerpo fatigado

(F. Grande)

625) Odio al musgo, el licopodio

(C.E. de Ory)

626) Quiero enseñar mis fuentes oratorias

ora tapiar el viento a las urracas

ora pretil...

(C. E. de Ory)

627) como un salmo desalmado

(G. A. Carriedo)

628) Coje presos a los caracoles

que le comen las coles

(M. de Unamuno)

629) Sanguinarias sanguinosas sanquijuelas al olor

(M. de Unamuno)

630) ... poeta maldito de la burguesía y de la policja y simplemente de la ClA

(B. de Otero)

631) Canto el Cantáabrico

(B. de Otero)

Cuando el juego paronomásico se extiende al derivado auténtico de uno de los parónimos - que se halla in absentia -, se establece una relación fónica tripartita:

632) maletilla de las letras

(G. Fuertes)

letra $\rightarrow$ letrilla / (ma)letilla 
633) Palabreria de los libros

\section{(J. Hierro}

libro $\rightarrow$ libreŕa / (pa)labrera

634) Palo sin polilla

(G. Fuertes)

palo $\rightarrow$ palillo / polilla

635) $Y$;ay, qué moro moriria (!)

(G. A. Carriedo)

moro $\rightarrow$ morería / moriría

Un efecto lúdicro intenso se consigue mediante la acumulación de paronomasias:

636) Piedras de arroye arrollas

y arrullas, hollas, hallas, mulles piedras

(Casanova de Ayala)

637) Yo

remera de barcas

ramera de hombres

romera de almas

ramona.

pa'servirles

(G. Fuertes)

638) Daba pasos, daba pesos,

pisos daba, daba posos

(G. A. Carriedo)

639) delia-dalia dalilía

y ola velo vela helada

(R. Alberti)

640) por mi porta,

a la guerra

por ti parte

por ti porto

de la guerra

limpio parte

(R. Alberti) 
641) Fulanos machistas.

Fulanas marchitas

(...)

La ganadera ganadora

La saga de los algo.

La sarta de la suerte.

La mente de mentira.

El corazón acorazado.

(G. Fuertes)

642) Blusa de Blasa.

Sólo en el polo.

Garra de guerra.

Qué asco de casce.

Cuento que encanta.

Pato a la puta.

Pena de pene.

Pancha y su Pancho.

Vista a la bestia.

la Tía Teta.

Los senos sanos.

Siete de sota.

Leche en el lecho.

Nicho en la noche.

(G. Fuertes)

\section{RESUMEN}

De acuerdo con lo indicado en los epígrafes 5 y 6 , pueden distinguirse las siguientes variedades de paronomasia:

\subsection{Paronomasia de inclusión continua}

a) Por inversión:

643) ni equiVALE a una VELA, aunque produjo muchas de par en par. Es el reflujo

(M. Hernández) 
644) Y pasa, y se queda. Y se alza, y vuELVE siempre LEVE, siempre aqui, siempre allí..

(V. Aleixandre)

645) Como PALOMA o aMAPOLA o beso

(P. Neruda)

646) Me siento mejor. Sin EIEBRE, y EERY IEnte

(C. Vallejo)

647) del imberbe del ALMA

que infLAMA su pasión desconsolada

$$
\text { (J. Á. Valente) }
$$

648) y el ron caliente en los vasos de estaño redondo se ALZA

como enLAZAda corona de laurel y galones

(P. Gancfa Baena)

649) AMOR deMORAdo. Amor en los dedos que pulsa sin ruido (V. Aleixandre)

650) TERSITes bello y TRISTE

(C. E. de Ory)

651) Y tus palabras que seRENAs ERAN como si a nadie las dijeses

(F. Frines)

652) Cabral POTENte

PONTE cerca de mí...

(C. E. de Ory)

653) nUEVA AVE

(G. Fuertes)

654) BALCONes en BLANCQ

(J. Guillén)

655) EaROLES ELORES coronas

(J. R. Jiménez)

656) ... en confusión de rotos ARREOS y CORREAS

(M. Machado) 
657) brota LUZ

¡Erótica aZUL!

(G. Fuertes)

b) Por adición (o supresion):

658) Sólo un rUMOr, un hUMO desprendido

(Á. González)

659) Que profusión de vida y muerte mata

y resuCITA, despide y CITA, y triunfa y llama

(V. Aleixandre)

660) Desde alli te contemplo en PIE y en PIEdra

(J. A. Valente)

661) Las palabras se llenan de un hipo triste de animal ahíto, de un HIPO de HIPOpotamo tardío

$$
\text { (J. Á. Valente) }
$$

662) ¿Perfuma aún más rosas la alba frente del HADA de tu sueño ADAmantino?

(A. Machado)

663) ¿Qué sitio ESTE sin tregua? ¿Qué huESTE, qué altas lides...?

(C. Rodríguez)

664) Nada es tan necesario al hombre como un trozo de MAR $y$ un MARgen de esperanza...

(B. de Otero)

665) ni cómo vida y muerte - agua y fuego- hermanadas

YAN socaVANdo nuestra roca

(J. Hierro)

666) ¿Cuán pronto de otra VIDA una se olVIDA!

(M. de Unamuno)

667) Mi paranoia de LOLAo y Averno ihOLA pata de oro, hOLA marea (!)

(C. E. de Ory)

668) ... desNUDO de repente, NUDO de amor, palabra desatándose dentro (!)

(L. Panero) 
669) Si ave nueva te da CITA: resuCITA

(G. Fuertes)

670) con los ojos malos viene San FranCISCO con el cuerpo y el alma hecha CISCO

(G. Fuertes)

671) ¡Oh musgo! ¡Oh jaramago! ¡Oh parietaria -hIEDRA a la pIEDRA - , bajo el sol recio!

(M. Machado)

672) Te abre los brazos bELLA por el surco échate en ELLA, labrador...

(G. Fuertes)

673) plácidamente ANCHA hacia La MANCHA

(L. Panero)

674) ¡qué hONDO estanque redONDO encontrarían!

(E. Prados)

675) Los ojos ven hacia dentro, buscando sombra, $y$ al RAS del RAStrojo, los rebaños se responden al balar

(L. Panero)

676) buril en mano, sobre el ORO IlORO

(M. Machado)

677) Naves de Sanlúcar salen

PARA el PARAná

(R. Alberti)

678) (...)

ALTO

CObALTO

(R. Alberti)

679) Mutilaron tus líneas como brazos abiertos en la página: tACHAda por el hACHA de un neotorquemada

(B. de Otero)

680) y no me hIERA fIERA luz del cielo

(M. de Unamuno) 
681) FLORencia - FLOR de música y aroma-

(M. Machado)

682) hUEV A de nUEVAs vidas y de canto

(M. de Unamuno)

683) SOLapada sin SOL

(G. Fuertes)

684) Ella sigue en su baranda, verde carne, pelo verde, soñando en la MAR aMARga

(F. García Lorca)

685) CampeSINO duro SINO

(G. Fuertes)

686) en un corral por ser huMANO de una MANO

(C.E. de Ory)

687) ten valor, TEN valor

InTENta seducirme

(C. Rodríguez)

688) junto al MAR aMARgo

(A. Machado)

\subsection{Paronomasia de inclusión discontinua}

a) Por inversión:

689) BlanCURAs en CURYA

(J. Guillên)

690) estRiBILLQ $\sin$ BRILLQ

(G. Fuertes)

691) Fuego voraz sin AMPARO, sARAMPiÓn sin remedio

(R. Alberti)

692) te acoraza, te dESYELA,

te ELEVA

(G. Fuertes) 
693) y repetir un TONO admONiTOrio

(Á. González)

694) si te teme que la VEREDA VERDAdEra haya quedado atrás

(A. González)

695) y tanto amor se habrá puesto como una CoSEchA SECA

(F. Grande)

696) ACuaRELadOS de hierba los ALCORES, y los trigos

(R. de Garciasol)

697) la tierra ENVIlecIDA por la ENVIDIA

(M. de Unamuno)

698) Yo voy echando verdades que NADA son, vANiDAdes al fondo de mi crisol

(A. Machado)

699) este disco que gira y gira en el silencio ConSUMIdA su MÚSICA...

(J. Hierro)

700) aBRIrÁS la ventana a la BRISA

del alba

(B. de Otero)

701) ... y de la Muerte fue sudario de $A M O R$ al inMOLARla

(M. de Unamuno)

702) ... el miedo instaba a alzarse en un VERDOR de VERDeROnes

(R. Alberti)

703) de la mirada, el pie, la voz, la VENA que me desVELAN versos y raíces!

(R. de Garciasol) 
704) chorreras silenciosas, EmPINADOS PEINADOS, viejísimos terciopelos

(V. Aleixandre)

705) Al cobrar pie entre los MIRTOS MIsTeRios $\underline{\mathrm{OS}}$

(L. Cernuda)

706) éste es mi grato peso, que me buscara abajo PARA

PAjARo

(C. Vallejo)

707) Tiendas de paz, BRiZAdOS pabellones, eran sus BRAZOS, como llama al viento

(B. de Otero)

708) La pluma de AVE VuElA, a ras del blanco intacto

(V. Aleixandre)

709) Azulada sonrisa aSomANDO en sus ONDAS

(L. Cernuda)

710) Daba aplausos de vuelos, como una SELVA eLeVAndoSE

(V. Aleixandre)

711) Inclina la cabeza, y en su gesto

NADA ADiviNAría nadie...

(F. Brines)

b) Por adición (o sustracción):

712) con andar cAnSiNO de ASNO

(B. de Otero)

713) ... fronda

de turbias ERENTES y suERiENTES pechos

(B. de Otero)

714) ... Los amantes

gozan de un fiel hASTIO y el fASTIdiO

torna en hogar la ufana habitación

(F. Brines)

715) Con RESTauradOS RESTOS y reliquias

(L. Cernuda) 
716) La MANO delicada MArcaNdQ con un dedo

(L. Cernuda)

717) AMA Felipe la cAlMA, la quietud contemplativa

(L. Cernuda)

718) y otras CALVAS en otras CALaVerAS

(A. Machado)

719) acudíamos entonces en busca de OTROS rQsTROS

(Á. González)

720) y su lúgubre azul de estandarte en naufragio se puebla de PLAneTAs de PLATA enroquecida

(P. Neruda)

721) un profesor ilustre dedujo de unas plumas mAnciLLADAS,

hALLADAS entre sangre

cerca de un arrozar
(Á. González)

722) el que AhoRA asciende al ARA

(J. Á. Valente)

723) junto al tren que SILBA

ŚLaBAs de infancia

(L. Panero)

724) Perfección del círculo

CIRCulO del CIRCO

(J. Guillén)

725) Lleva en la mano diestra un BULTQ enVUeLTO en un pañuelo blanco

(A. Machado)

726) el talón se nos tiñe de UVA nUeVA, y ormos desbordar bien sé qué ganas

(C. Rodríguez) 
12.3. Paronomasia de intersección continua

a) Por inversion:

727) Se ve, desde los ASTOs

la trASTORnada luz

(F. Brines)

728) Los problemas

me sACUDEN y fECUNDAn

(G. Fuertes)

729) dESNUda VENUS cierta

(P. Salinas)

730) AROma de gro dORAndo

(J. Hierro)

731) y tu nariz, animal solitario, oYEJA salVAJE

(P. Neruda)

b) Por conmutación:

732) PESe a este sol que PESa sobre mis coyunturas más graves

(V. Aleixandre)

733) aLAS de oLAS en mi azul

(V. Huidobro)

734) en el sitio y la hoRA de la iRA

(Á. González)

735) ... no habrá PROSe (y será entonces una PROSa aparente, purificada de todo lirismo)

(L. M. Panero)

736) [Leo el Apocalipsis, lo releo, $y$ en su eterna MAREa, me MAREo

(M. de Unamuno)

737) que ahora cIERRA la tIERRA

(M. de Unamuno)

738) falta de rUMBO,

de tUMBO en tumbo

(M. de Unamuno) 
739) En tu camino un cINCEL,

pINCEL se hubiera vuelto

$$
\text { (R. Alberti) }
$$

740) Salte el YOCAblo que equiVOCA

$$
\text { (R. Alberti) }
$$

741) Mi cuerpo de nOBLE rOBLE

$$
\text { (G. Fuertes) }
$$

742) Alza, alza tu pAÑO;

AÑOs, sustancia del olvido...

(F. Grande)

c) Por adición (o supresión):

743) ... Que las fauces del calendario

te tributen a to, mas no al rumor solemne de tu olVIDo, tu VIDa

$$
\text { (F. Grande) }
$$

744) Se nos ha entrEGADO un IEGADO de sueño que nos llega a las manos...

$$
\text { (C. Bousoño) }
$$

745) La huella de los dedos enamorados Que, bajo su caricia, lo ANIMAran con candor ANIMAl y con gracia terrestre

$$
\text { (L. Cernuda) }
$$

746) Bambolea el VIENTo un VIENTre de gritos anteriores al mundo (R. Alberti)

747) El mundo tiene SORDas preguntas y deSORDen

(F. García Lorca)

748) felices en el vuelo me hunden y me huNDen en la hoNDa llamada de la carne a la carne

(R. Morales)

749) (iDEA, alDEA o persona)

(G. Fuertes)

750) te LLAMO LLAMa

(G. Fuertes) 
751) quemar un TRAJe de TRÁGica hiedra

(L. M. Panero)

752) ... enCIMA

de las CIMAs de nuestras almas

(J. Hierro)

753) esta enfERMTTA de TERMITA

(G. Fuertes)

754) desde la mucheduMBRE que padece haMBRE y persecución...

(J. Á. Valente)

12.4. Paronomasia de intersección discontinua:

a) Por inversión:

755) Aurora en acto,

EaCILIDAD EeLICIDAD sin tacha

(J. Guillén)

756) Quisiera coNvERTIrme en tu IINTERna

(G. Fuertes)

757) Con sillares de música ALZAbA su ALcAZAr

(J. Hierro)

758) y aROMas de un MOBo jardín andaluz

(A. Machado)

759) Ya las golondrinas chillan. Pasaron del blanco invierno, de NEYaSCAS y VENtiSCAS los crudos soplos del infierno

(A. Machado)

760) donde flotan ALMIArES, AnIMALES que aúllan

(R. Molina)

761) El AMULETO; el LAMEnTQ: la madre canta... (V. Aleixandre)

762) Alli ALZAbaN sus LANZAs de frescor vigilante las tiernas aspidistras

(R. Morales) 
763) Y parece que está el universo enCAnTaDQ, ToCADQ de gracia...

$$
\text { (J. Hierro) }
$$

764) la noche SALe SOLa, como creciente viuda

(P. Neruda)

765) Arrebol,

REVOLETA de ARREBOLES

(R. Alberti)

766) [Con poca fe, con las creencias rotas como un MAdERQ en la MAREa

(F. Brines)

767) ¡Oh, PENa imPuNE!

(G. A. Carriedo)

768) nunca ROÑaDA flor de los ReDAÑOs

(M. de Unamuno)

769) de bEATA de pETAcA

(G. Fuertes)

b) Por conmutación :

770) se dan CASoS, aunque nunca se dan CASaS

(G. Fuertes)

771) Bastaba un CIEIO CIEgO, un pobre viento

(J. R. Jiménez)

772) Entre las hojas brotan NuBES, NaVES, espacios reducidos

(M. Hernández)

773) ¡Con el SoL y la SaL que hay en tu llanto!

(A. Machado)

774) $Y$ aquí concluye esta intrincada CaRTA;

CoBTA será tal vez para el amigo

(M. de Unamuno)

775) y espumas

de mágicos lagos en tristes JArdINES, $y$ enfermos JAzmINES

(A. Machado)

776) y tu $\underline{Y o Z}$ otra $\underline{Y} e Z$ se levanta en la sombra

(P. García Baena) 
777) quiere $\triangle A B e B S A B O R$ de tus redaños

(M.de Unamuno)

778) Se hagan mis QJoS dos hoJaS de yerba

(M. de Unamuno)

779) ¡Cuántas humanidades IUsTAS JUnTAS!

(C. Vallejo)

780) el llanto de los MoNOS tiene MeNOS de un año

(L. M. Panero)

781) Como se vuelve el LAgO del LAdO de la selva

(L. Panero)

782) RUeDa sin RUiDo

(L. Panero)

783) En busca de otro mar EmBaTES de rEBoTES

(J. Guillén)

784) SoLA en la SaLA

(G. Fuertes)

785) La tarde caliza Que fue polvareda se ExTREmA, se EnTREgA

Diafanas vistillas

(J. Guillén)

786) ¡Oh ViEJAS moscas voraces como aBEJAS en abril (!)

(A. Machado)

787) y regresas al mundo llena de SaL y SoL

(P. Neruda)

c) Por adición (o supresión):

788) cambios, MUTACIONES MediTACIONES

(G. Fuertes) 
789) Soto, RaSO, era

ReSOl en la aldea

(J. Guillén)

790) teRReSTe RaSTro de vida

(C.E. de Ory)

791) Se miente más de la cuenta por FAlTA de FAnTAsía

(A. Machado)

792) Tu presencia de espuma LaVA, eLeVA. hace flotar las cosas y los seres

(Á. González)

793) ¡Mis hOMBRos de hOMBRe de mar!

(R. Alberti)

794) tocamos la SuTURA. esa coSTURA (a veces un remiendo, a veces un bordado)

(C. Rodríguez)

795) Tu EAz es tu aEÁn

(J. Guillén)

796) BRIzAba una BRIsA queda

(M. de Unamuno)

797) Tú, y tú, y yo, nos TuRNaremos

en ToRNOS de cristal, ante la muerte

(B. de Otero)

798) con mayo, de AZUcEnaS

=AZUIES y amarillas (\#)

(J. R. Jiménez)

799) BAMPosadQ PAMPerQ

(S. Sernesi)

800) ... y el cLMMA iLMMitAdo de un estío

(L. Cernuda)

801) $Y$ yo, sentado en un silla, silaba a StLaBa les SILBo en los oídos

(B. de Otero) 
802) se acercan secas crestas

MORAndo en la meMORiA

(C.E. de Ory)

803) a lo mejor su NueVA

NoViA de cobre y cebo

\section{(S. Sernesi)}

804) no era el TORvQ presentimiento de mi vida en su polvo no era el conTORnQ bien preciso donde la sangre un día acabaría coagulada...

(V. Aleixandre)

805) nunca me iré de aquí: fue muy cerTeRO el TiRO

(C. Rodríguez)

12.5. Paronomasia de exclusion:

806) y en la QNU hablaba UNO

(B. de Otero)

807) ... El agua es SOLA

bajo las QLAS; es la pesadumbre

de lo eterno...

(M. de Unamuno)

808) Menudo menú

...

y ragú

- RABÚ de rabo de BURRA

(G. Fuertes)

809) por mi PORTA,

a la guerra

por ti PARTO

(R. Alberti)

810) Del abierto BALCÓN al BLANCO muro va una franja de sol anaranjada

(A. Machado)

811) lucientes de húmedo brillo el MORRO ROMO

(M. de Unamuno) 
812) ¿Seréis la cautiva del moro GAZUL?

Dijéraislo, y pronto mi amor os diría

el son de mi GUZLA y la algarabía

más dulce que oyera ventana moruna

(A. Machado)

813) ¿Nos dora siempre el SOL LOS sueños de otro suelo?

(L. Cernuda)

814) brinquiños diminutos sobre el pétalo de la otra ROSA, reina, RASO, lumbre

(P. García Baena)

815) Y saber que era ETERNO el hombre ENTERO

(L. Panero)

816) ASIDO A DIOS como a un trapecio a punto de infinitamente arrojarme hacia el mar

(J. A. Valente) 